PABLO SALVANHA

MODELO PARA ANÁLISE DE DESEMPENHO DO PROCESSO DE REPLICAÇÃO DE DADOS EM PORTAIS DE BIODIVERSIDADE 
PABLO SALVANHA

\section{MODELO PARA ANÁLISE DE DESEMPENHO DO PROCESSO DE REPLICAÇÃO DE DADOS EM PORTAIS DE BIODIVERSIDADE}

Dissertação apresentada à Escola Politécnica da Universidade de São Paulo para obtenção do titulo de Mestre em Engenharia. 
PABLO SALVANHA

MODELO PARA ANÁLISE DE DESEMPENHO DO PROCESSO DE REPLICAÇÃO DE DADOS EM PORTAIS DE BIODIVERSIDADE

Dissertação apresentada à Escola

Politécnica da Universidade de São Paulo para obtenção do titulo de Mestre em Engenharia.

Área de Concentração:

Sistemas Digitais

Orientador:

Prof. Dr. Pedro Luiz Pizzigatti Corrêa 
Este exemplar foi revisado e alterado em relação à versão original, sob responsabilidade única do autor e com a anuência de seu orientador.

São Paulo, 07 de janeiro de 2010.

Assinatura do autor

Assinatura do orientador

\section{FICHA CATALOGRÁFICA}

Salvanha, Pablo

Modelo para análise de desempenho do processo de replicação de dados em portais de biodiversidade / P. Salvanha. -ed.rev. -- São Paulo, 2010.

$65 \mathrm{p}$.

Dissertação (Mestrado) - Escola Politécnica da Universidade de São Paulo. Departamento de Engenharia de Computação e Sistemas Digitais.

1. Análise de desempenho 2. Banco de dados distribuídos 3. Sistemas de informação 4. Biodiversidade I. Universidade de São Paulo. Escola Politécnica. Departamento de Engenharia de Computação e Sistemas Digitais II. t. 
À minha família, sem ela seria impossível chegar até aqui, e a Fernanda, minha paixão, a qual me deu apoio em todos os momentos. 


\section{AGRADECIMENTOS}

Ao meu orientador, Prof. Dr. Pedro Luiz Pizzigatti Corrêa, que acreditou no meu potencial desde o principio, e me guiou para que este trabalho pudesse se tornar uma importante contribuição cientifica para a área.

À minha família (Irineu, Maria Doraci e Fabricio) que me incentivou, apoiou, educou de forma a me tornar quem eu sou. Sem isso com certeza eu não teria chegado até esta etapa tão importante da minha vida.

À minha namorada Fernanda Canto Prado por ser uma pessoa maravilhosa a qual pude contar sempre que precisei e sempre acreditou no meu trabalho e no meu potencial. E também a lly e a Akyra, que são como filhas para nós.

Às equipes de desenvolvimento do INBio e GBIF, em especial Tim Robertson e José Cuadra que me ajudaram nas implementações realizadas no portal IABIN-PTN.

Aos professores do LAA, em especial ao Prof. Dr. Antonio Mauro Saraiva, pelas oportunidades e pelo auxilio na evolução de meus trabalhos.

Aos colegas e amigos do LAA, em especial, Guilherme, Jorge, Diogo, Etienne, Leandro Halle, Paulo e Edson, que sempre me ajudaram nos desenvolvimentos e nas elaborações das pesquisas.

À meu companheiro de viagem e estudos Fernando Elias Correa que compartilhou de todos os momentos de meu mestrado, desde as dificuldades até os desfechos.

Aos professores e amigos do COTIP, em especial ao Prof. Sergio Dias Aguiar, Prof. Anderson Rossi e Prof. Marcos Joel Leite, por compartilharem comigo os desafios da jornada acadêmica.

À Deus por ter iluminado meu caminho sempre, e ter me dado forças nos momentos de dificuldades. 


\section{RESUMO}

Atualmente muitas instituições mantêm coleções de espécimes biológicas, e através de ferramentas computacionais digitalizam e disponibilizam seus dados para acesso através de portais de dados de biodiversidade. Um exemplo deste tipo de ferramenta é o portal de espécimes utilizado pelo GBIF (Global Biodiversity Information Facility), que centraliza em suas bases de dados milhões de registros, provenientes de instituições de diferentes localizações. A replicação das bases de dados locais nos portais é realizada através da utilização de protocolos (DiGIR / TAPIR) e esquemas de dados (DarwinCore). Entretanto a execução desta solução demanda uma grande quantidade de tempo, englobando tanto a transferência dos fragmentos de dados como o processamento dos mesmos dentro do portal. Com o crescimento da digitalização de dados dentro das instituições, este cenário tende a ser agravado cada vez mais, dificultando assim a manutenção de dados sempre atualizados dentro dos portais. Esta pesquisa propõe uma análise do processo de replicação de dados com objetivo de avaliar seu desempenho. Para isto é utilizado o portal de biodiversidade de polinizadores da IABIN como estudo de caso, o qual possui, além da replicação de dados convencionais o suporte a dados de interação. Com os resultados desta pesquisa é possível simular situações antes da efetivação das mesmas, prevendo assim qual será o seu desempenho. Adicionalmente estes resultados podem contribuir para melhorias futuras deste processo, visando a diminuição do tempo necessário da disponibilização dos dados dentro de portais de biodiversidade.

Palavras-chave: Informática para a biodiversidade. Banco de dados distribuídos. Replicação de dados. Análise de desempenho. Polinizadores. 


\begin{abstract}
Currently many institutions keep collections of biological specimens, and through computational tools they digitalize and provide access to their data through biodiversity data portals. An example of this tool is the specimen's portal used by GBIF (Global Biodiversity Information Facility), which focuses on its databases millions of records from different institutions around the world. The replication of databases in those portals is accomplished through the use of protocols (DiGIR / TAPIR) and data schemas (DarwinCore). However the implementation of this solution demands a large amount of time, encompassing both, the transfer of fragments of data as processing data within the portal. With the growth of data digitalization within the institutions, this scenario tends to be increasingly exacerbated, making it hard to maintenance the records up to date within the portals. This research proposes analyze the replication process data to evaluate its performance. To reach this objective is used the IABIN biodiversity portal of pollinators as study case, which support both situations: the conventional data and the interaction data replication. With the results of this research is possible to simulate situations before its execution, thus predicting what will be its performance. Additionally these results may contribute to future improvements of this process; in order to decrease the time required to make the data available in the biodiversity portals.
\end{abstract}

Keywords: Biodiversity informatics. Distributed databases. Data replication. Performance analysis. Pollinators. 


\section{LISTA DE ILUSTRAÇÕES}

Figura 1 - Integração dos pontos distribuídos através da rede de computadores (baseado em figura de Ozsu e Valduriez, 1999).

Figura 2 - Entradas e saídas de uma integração de banco de dados (baseado em figura de Batini; Lenzerini e Navathe, 1986) 10

Figura 3 - Arquitetura de alto nível do DiGIR (baseada de DIGIR, 2009) ............... 13

Figura 4 - Requisição de dados usando protocolo TAPIR .................................... 15

Figura 5 - Exemplo de mensagem de retorno usando TAPIR ........................... 16

Figura 6 - Página principal do portal do GBIF (GBIF, 2009) .............................. 17

Figura 7 - Camada MVC utilizada pelos componentes do portal GBIF .................. 19

Figura 8 - Arquitetura proposta para o atual sistema TAPIR / DiGIR do portal de polinizadores

Figura 9 - Etapas do processo de replicação de dados entre provedor e o portal ... 23

Figura 10 - Interface de configuração do provedor TAPIR 25

Figura 11 - Pontos de notificação nos códigos do portal e provedor. 26

Figura 12 - Resultados da análise no cenário 1 (provedor local) .......................... 27

Figura 13 - Resultados da análise no cenário 2 (provedor no Brasil)..................... 28

Figura 14 - Resultados da análise no cenário 3 (provedor internacional) ............... 29

Figura 15 - Mapeamento dos campos do provedor no TAPIR 36

Figura 16 - Tela com as configurações do provedor TAPIR usadas para o provedor CEPANN

Figura 17 - Mapeamento dos dados de interação do provedor TAPIR do CEPANN39 Figura 18 - Tela com as configurações do provedor TAPIR de interação do CEPANN

Figura 19 - Gráfico com os resultados dos custos de cada processo obtidos nos cenários para testes 45

Figura 20 - Modelagem do banco de dados local do portal 55

Figura 21 - Trecho incluído diretamente no código do portal GBIF 58

Figura 22 - Modelo de saída (output model) adotado para metadados de interação59

Figura 23 - Visualização de exemplo da tabela "data_provider" 61

Figura 24 - Visualização de exemplo da tabela "resource_access_point" 62 
Figura 25 - Listagem de esquemas disponíveis para uso no portal ....................... 62

Figura 26 - Vínculos estabelecidos entre os RAP e os esquemas de dados ........... 63

Figura 27 - Listagem de executores existentes no módulo portal-index .................64 64 


\section{LISTA DE TABELAS}

Tabela 1 - As constantes utilizadas nas formulas e suas origens. ....................... 30

Tabela 2 - Campos variáveis envolvidos nas fórmulas ...................................... 31

Tabela 3 - Fórmulas de apoio para o modelo matemático .................................... 32

Tabela 4 - Comparativo de resultados reais e obtidos através do modelo matemático

Tabela 5 - Resultados reais obtidos no processo de replicação do CEPANN (DwC)

Tabela 6 - Dados variáveis para aplicação no modelo matemático

Tabela 7 - Resultados reais obtidos no processo de replicação do CEPANN (interação)

Tabela 8 - Dados variáveis para aplicação no modelo matemático

Tabela 9 - Comparativo dos resultados reais e propostos pelo modelo matemático42

Tabela 10 - Cenários para testes de comparação de custos 45

Tabela 11 - Comparação na compactação de um pacote de dados trafegado pelo provedor 


\section{LISTA DE ABREVIATURAS E SIGLAS}

AOP Aspect Oriented Programming

CALFLORA California Plants

DAO Data Access Objects

DiGIR Distributed Generic Information Retrieval

DTO Data Transfer Objects

DwC DarwinCore

GBIF Global Biodiversity Information Facility

IABIN Inter American Biodiversity Information Network

IABIN-PTN IABIN - Pollinators Thematic Network

IB Informática para Biodiversidade

IBUSP Instituto de Biociências da USP

IDE Integrated Development Environment

LAA Laboratório de Automação Agrícola

MVC Model View Controller

OSI Open Systems Interconnection

PN Ponto de notificação

RMI Remote Method Invocation

SQL Structured Query Language

TAPIR TDWG Access Protocol for Information Retrieval

TDWG Taxonomic Database Working Group

UDDI Universal Description, Discovery and Integration

URL Uniform Resource Locator

XML eXtensible Markup Language 


\section{SUMÁRIO}

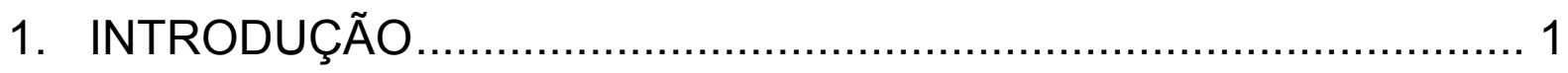

1.1. Informática para a biodiversidade ................................................ 1

1.2. Justificativa e Motivação .................................................................. 2

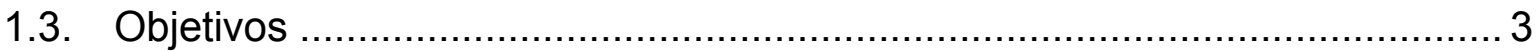

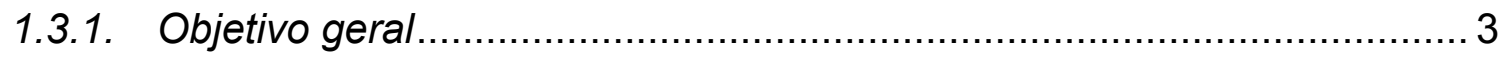

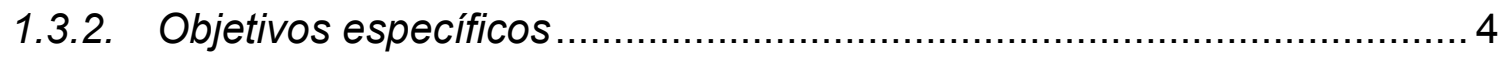

1.4. Materiais e Métodos ........................................................................... 4

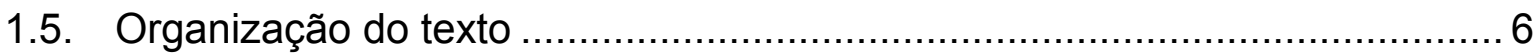

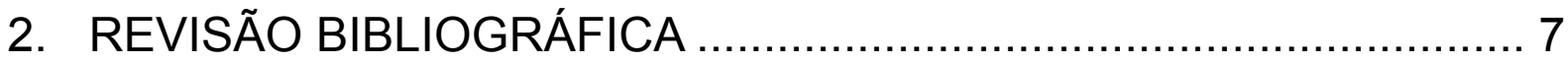

2.1. Bases de Dados Distribuídas de Biodiversidade .................................... 7

2.1.1. Protocolos para gerenciamento de réplicas .................................... 11

2.2. Portal de Biodiversidade GBIF ........................................................ 16

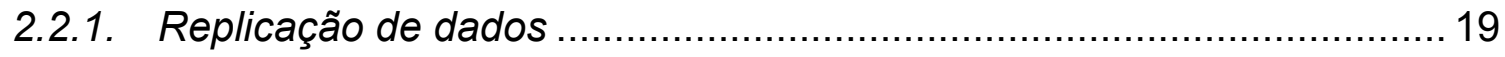

2.3. Método para análise de desempenho ................................................ 20

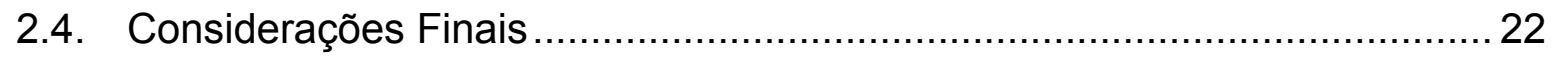

3. MODELO PARA ANÁLISE DE DESEMPENHO ......................... 23

3.1. Criação das diferentes condições do processo...................................... 24

3.2. Banco de dados de amostra e os pontos de notificação............................ 25

3.3. Execução dos testes e os resultados ............................................. 26

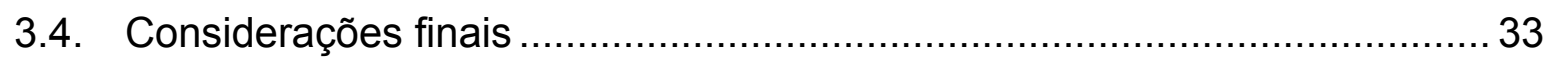

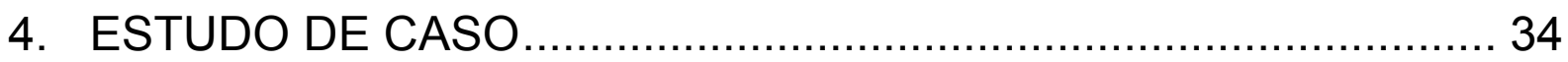

4.1. Configurações do provedor de dados singulares ................................ 35

4.2. Processo de replicação realizado no provedor de dados singulares ............ 37

4.3. Aplicação da fórmula no provedor de dados singulares ......................... 38

4.4. Configurações do provedor de dados de interação .................................. 39

4.5. Processo de replicação realizado no provedor de dados de interação........ 40

4.6. Aplicação da fórmula no provedor de dados de interação .......................... 41

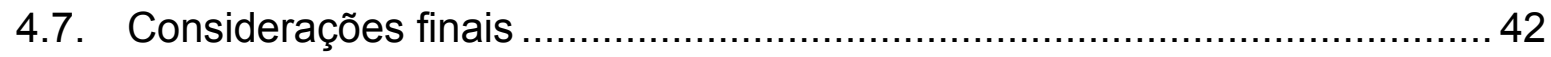




\section{DISCUSSÃO DOS RESULTADOS}

5.1. Discussão sobre os resultados obtidos com a utilização da fórmula 43

5.2. Discussão sobre os custos entre provedor, portal e rede 44

5.3. Discussão sobre os resultados do estudo de caso 46

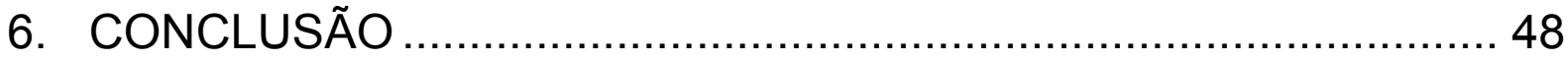

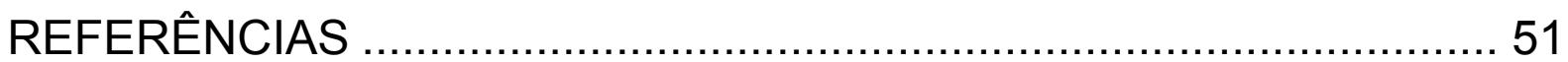

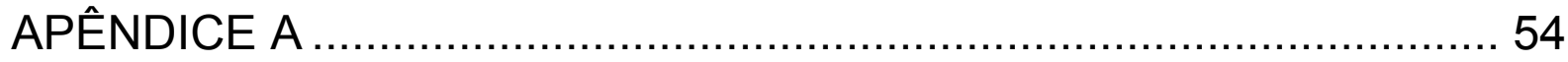

7. Implementação do suporte a dados de interação …………………….......... 54

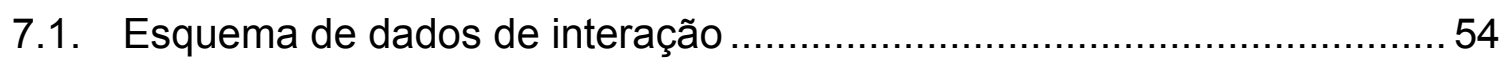

7.2. Adequação do código fonte baseado no portal GBIF ................................55

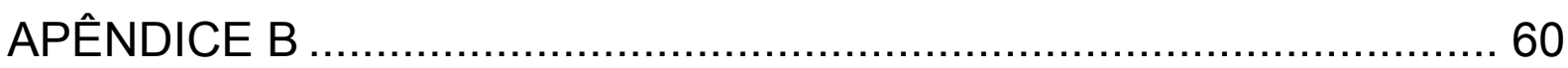

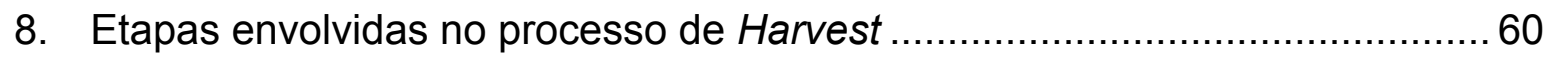

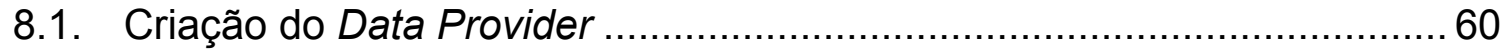

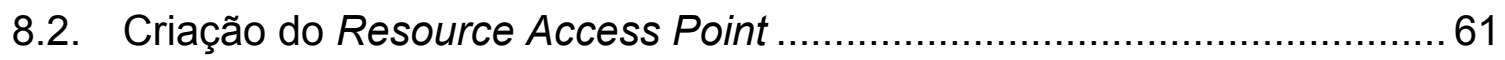

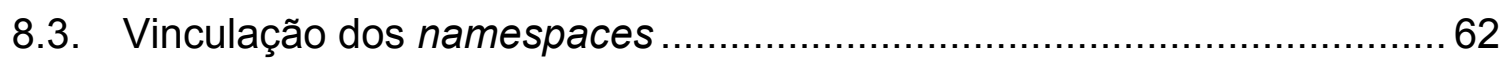

8.4. Solicitação e obtenção dos resources do provedor ...................................63

8.5. Solicitação e obtenção dos dados de indexação...................................... 64

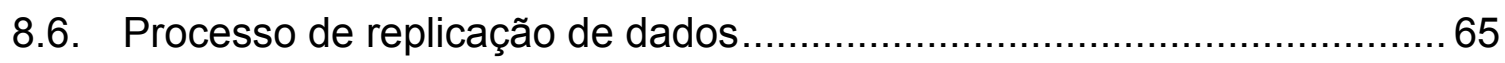

8.7. Processo de consolidação dos dados replicados .................................... 65

8.8. Rotinas para contagem e readequação dos dados ....................................65 


\section{INTRODUÇÃO}

\subsection{Informática para a biodiversidade}

No decorrer dessas últimas décadas foi possível constatar uma evolução no que se refere ao processamento e armazenamento de informações, sendo ambos aplicados às mais diversas finalidades. Essa evolução amplia a necessidade de sistemas mais rápidos e eficientes para consultar grandes quantidades de dados. Tal fato não é diferente para os dados da biodiversidade, que tem como ponto mais relevante a informação em si, pois é através desses dados que os pesquisadores conseguem agregar valor a seus trabalhos e evoluir em suas pesquisas.

A área de pesquisa da computação e biologia que trata de aspectos de armazenamento, compartilhamento e análise de dados da biodiversidade é denominada de Informática para a Biodiversidade (IB), um termo usado para determinar ferramentas computacionais que auxiliam esses processos. Como exemplo, pode-se citar a digitalização desses tipos de dados, que segundo Canhos et al., (2004), teve origem em um trabalho cooperativo realizado pelos herbários australianos em meados da década de 70 .

As instituições que realizam as digitalizações de seus dados e fornecem os mesmos para compartilhamento com outras instituições de áreas afins, são conhecidas como publicadoras de dados. Já no âmbito computacional, a disponibilização desses dados para acesso remoto é realizada pelos provedores de dados, que são a forma com a qual os portais conseguem executar a replicação dos dados para suas bases locais. Uma vez replicados esses dados entre os provedores e o portal, existem duas situações que requerem uma nova comunicação entre as partes. A primeira é referente a dados incrementais, que ocorre quando o provedor recebe novos registros a serem publicados em sua base de dados, já a segunda é quando a instituição atualiza ou aumenta o detalhe de registros já publicados anteriormente. 
Uma das principais ferramentas computacionais utilizadas para compartilhamento de dados de biodiversidade são os portais (citação verbal) ${ }^{1}$, que centralizam informações obtidas de provedores espalhados por todo o mundo. A replicação dos dados do provedor é a solução atualmente utilizada pelo portal do GBIF (Global Biodiversity Information Facility) (GBIF, 2009), que centraliza milhões de registros de espécimes obtidos de provedores de dados, tais como museus, herbários, universidades, entre outros. Outro portal que utiliza esse mesmo formato é o portal de dados de polinizadores da IABIN (Inter-American Biodiversity Information Network) (IABIN, 2009). É importante destacar o agravante no que se refere à heterogeneidade dos dados (campos com nomenclaturas diferentes) entre os diferentes provedores, além dos problemas convencionais de padronização de nomes (ex: tipo de interação) e informações comuns na área de biodiversidade (STEVENSON; MORIS, 2002), que são contornados por esses portais com o uso de esquemas de dados, que têm como principal objetivo a padronização dessas informações.

Durante o processo de replicação de dados é utilizado o esquema de dados DarwinCore (DwC) em conjunto com protocolos, como DiGIR (Distributed Generic Information Retrieval) e TAPIR (TDWG Access Protocol for Information Retrieval), os quais foram desenvolvidos especialmente para transferência de dados entre os provedores e os portais de biodiversidade (DWC, 2009) (DIGIR, 2009) (TAPIR, 2009).

\subsection{Justificativa e Motivação}

Segundo SARAIVA apud. SOAM; SINGH (2003) o cenário mundial na área de biodiversidade é preocupante. Importantes espécies tanto de plantas como animais estão à beira da extinção, e este fato foi a principal motivação para a realização deste trabalho, com o objetivo de contribuir positivamente com pesquisas que buscam reverter esta situação alarmante.

Dentro do cenário de comunicação entre portais e provedores de biodiversidade, o uso da replicação de dados é de fundamental importância. A sua

\footnotetext{
${ }^{1}$ Informação obtida através de apresentações do Workshop de Informática para Biodiversidade realizado de forma agregada ao BNCOD na Universidade de Cardiff, 2008.
} 
evolução pode contribuir para a disponibilização mais rápida de dados que são compartilhados por pesquisadores da área.

Um dos fatores mais críticos neste processo de replicação usando os protocolos DiGIR e TAPIR e seus esquemas de dados é o tempo consumido entre o início e a finalização do processo. Portais como o GBIF, que utilizam da replicação de dados, necessitam de um acompanhamento desse processo para cada provedor envolvido, e o tempo necessário para a sua conclusão pode levar horas ou até mesmo dias (SALVANHA et al., 2009).

Assumindo-se que em outros cenários computacionais a transferência de informações (ex. banco de dados) pode ser realizada em um período de tempo comparativamente pequeno, qual seria a justificativa para este tempo maior no processo de replicação de biodiversidade? Poderia ser em relação à padronização com o uso de esquemas, ou os parâmetros de funcionamento dos protocolos, ou até mesmo um algoritmo não tão eficaz.

É para responder a essa pergunta que esta pesquisa se propõe a isolar as etapas de todo o processo e realizar testes reais, com o intuito de recolher dados que possam auxiliar nesta conclusão. Além de fornecer uma fórmula que possa ser utilizada para simular novas situações em cenários diferenciados.

O iminente aumento na quantidade de dados de biodiversidade por parte dos provedores (GRAHAM et al., 2004), e a presente dificuldade em manter informações valiosas para muitos pesquisadores, sempre atualizadas, serviram de motivação para a realização desta pesquisa. Os seus resultados, com certeza, poderão auxiliar trabalhos futuros que visem a tornar mais eficaz esse processo de replicação.

\subsection{Objetivos}

\subsubsection{Objetivo geral}

Esta pesquisa apresenta um modelo para simulação e análise de desempenho do processo de replicação de dados entre portais e provedores de dados de biodiversidade. 


\subsubsection{Objetivos específicos}

- Definir um modelo matemático para representação do custo da replicação de dados entre as bases de dados de provedores e portais;

- Validar esse modelo através de um estudo de caso de replicação de dados entre um provedor real e o portal de dados de espécies de polinizadores da América - IABIN-PTN (Inter-American Biodiversity Information Network Pollinators Thematic Network);

- Avaliar possíveis cenários de evolução de metadados e de protocolos de informática para biodiversidade e seu impacto no desempenho de replicação;

- Apresentar resultados em diferentes cenários e discutir sobre os mesmos de forma a gerar informações úteis para futuros trabalhos que tenham como objetivo melhorar o processo de replicação de biodiversidade;

- Abranger a análise de desempenho a dados de interação usados especificamente no portal de polinizadores da IABIN, e verificar sua eficiência comparativa com os métodos atualmente utilizados para dados singulares.

\subsection{Materiais e Métodos}

Para entender o processo de replicação de dados entre as bases de dados de provedores e portais de biodiversidade, utilizou-se a infra-estrutura computacional do projeto IABIN-PTN (detalhada melhor no capítulo 3), que mantém dados de polinizadores da América. Essa base de dados em Outubro/2009 contava com 7 provedores e mais de 280 mil registros (IABIN-PTN, 2009). Nesse estágio do projeto havia adicionalmente uma carga de dados proveniente do GBIF, os quais deveriam ser inseridos neste portal. Tal carga de dados era composta por mais de 800 mil registros e, a partir de um fragmento desta, foram desenvolvidos os cenários de testes.

Os softwares e tecnologias utilizados neste trabalho para a realização dos testes e criação de um laboratório prático foram:

- Sistema operacional Ubuntu 9.04 (Linux) - kernel 2.6.28-11 (32-bits);

- Banco de dados MySQL versão 5.0.75;

- Eclipse Galileo (build: 20090920-1017); 
- Java versão 1.6;

- Protocolo Tapir 0.6.1;

- DarwinCore 1.4 com extensões georeferenciais;

- PHP versão 5.0;

- Apache versão 2.2.3;

- Portal IABIN versão 1.0.

Para definir o modelo de custos a ser utilizado na realização deste trabalho, foram comparadas as características do definido por CORREAA (2002) e por OSZU (1999). Ambos possuíam características adequadas para serem utilizados neste trabalho, no entanto, foi adotado o uso do modelo de custos de replicação de dados definido por CORRÊA (2002), em função de ter sido desenvolvido para o uso com uma quantidade menor de variáveis e também, devido ao fato de não abranger a atualização de dados entre as partes, características que se identificam com o escopo deste trabalho.

Para a validação e ajustes do modelo de custos, definiu-se um laboratório alterando-se os principais fatores que interferem no desempenho: características da rede, volume de dados a serem replicados, tamanho dos pacotes e desempenho do provedor. Como citado anteriormente, foi criado um provedor para esta finalidade, com dados reais e características similares aos provedores utilizados pelos portais de biodiversidade, que foram utilizados em todos os cenários.

Os testes para elaboração do modelo foram executados diversas vezes sendo considerada sempre a média das amostras como resultado oficial, visando assim a aprimorar o modelo, evitando a interferência de situações excepcionais nos dados.

Após a definição do modelo, foi utilizado um estudo de caso real baseado em um provedor utilizado no portal de polinizadores da IABIN. Com esse provedor foi realizado o processo de replicação dos dados singulares, que possui as mesmas características dos provedores utilizados para gerar o modelo. Assim, foi possível validar a efetividade do mesmo em um novo cenário. Adicionalmente, foi realizado o estudo no processo de replicação dos dados de interação, que faz uso de um processo diferenciado (com outro esquema de dados e nova implementação dentro do portal), o objetivo deste teste foi verificar comparativamente a efetividade das mudanças realizadas para esta funcionalidade, uma vez que são utilizadas técnicas similares e o mesmo protocolo (TAPIR) em relação ao provedor de dados singulares. 
Com todos os testes realizados, foi possível obter uma série de dados inéditos, referentes ao desempenho da replicação de dados de biodiversidade. Tais dados possibilitaram gerar resultados comparativos, os quais foram discutidos neste trabalho, a fim de contribuir futuramente com a evolução deste processo.

\subsection{Organização do texto}

Esta dissertação é composta por cinco capítulos e dois apêndices, distribuídos na sequência a seguir:

- O capítulo 2 apresenta a revisão bibliográfica, abrangendo as tecnologias computacionais envolvidas neste trabalho, como os portais de biodiversidade, além de conceitos para métodos de análise de desempenho;

- O capítulo 3 apresenta todos os cenários e testes realizados para a obtenção de dados que geraram o modelo matemático. Além de apresentar o modelo em si, com a discussão de seus fatores e suas aplicações reais.

- O capítulo 4 apresenta o estudo de caso do portal de polinizadores da IABIN, demonstrando situações reais de processo de replicação de dados, tanto para dados singulares como para dados de interação e as medições realizadas;

- O capítulo 5 apresenta a discussão dos resultados referentes aos dados dos testes iniciais para formulação do modelo, assim como os resultados provenientes do estudo de caso;

- O capítulo 6 apresenta as conclusões e expectativas de trabalhos futuros;

- O apêndice $A$ apresenta quais foram as principais alterações realizadas com relação à implementação do portal, provedor e esquema de dados para o suporte à replicação de dados de interação;

- O apêndice B apresenta, em maiores detalhes técnicos, as etapas que vinculam e transferem os dados de um provedor para um portal baseado no projeto IABIN-PTN. 


\section{REVISÃO BIBLIOGRÁFICA}

As iniciativas de informatização no processo de catalogação de dados de espécime existem desde a década de 70 , no entanto o seu grande impacto ocorreu a partir da Internet (GRAHAM et al., 2004). A partir desse ponto, a informática para biodiversidade ganhou maior importância e reconhecimento. Este capítulo visa apresentar as tecnologias correlatas a este trabalho e as quais foram utilizadas como referência para a realização do mesmo, divididos nos seguintes tópicos:

- Bases de dados distribuídas de biodiversidade: Explanação sobre a estratégia de armazenamento de dados utilizada atualmente pelos fornecedores de tais informações;

- Protocolos para o gerenciamento de réplicas: Abordagem sobre os protocolos utilizados, assim como os metadados responsáveis pelo tráfego dessas informações;

- Portal de biodiversidade GBIF: A apresentação do modelo do portal GBIF, que é utilizado no estudo de caso deste trabalho e seu funcionamento;

- Método para análise de desempenho: Conceitualmente, qual técnica foi utilizada para viabilizar a extração de dados de desempenho durante o processo de replicação.

\subsection{Bases de Dados Distribuídas de Biodiversidade}

O conceito central de bancos de dados distribuídos é o uso de duas diferentes tecnologias para prover uma nova finalidade: trata-se do uso de sistema de banco de dados tradicional e da rede de computadores para o processamento distribuído.

Segundo Ozsu e Valduriez (1999), a grande motivação no uso do sistema de banco de dados é integrar os dados corporativos de forma centralizada, para um acesso mais direcionado e controlado. Dessa forma, é proporcionado um armazenamento de informações capaz de ser acessado por diversos sistemas legados, permitindo consultas e alterações de dados de forma organizada e controlada. 
No que se refere ao processamento distribuído (ou computação distribuída) Ozsu e Valduriez (1999) citam que tal tecnologia é utilizada para a formalização de diversos usos práticos, tais como: sistemas multiprocessados, processamento de dados distribuídos e rede de computadores. Basicamente, a tecnologia faz uso da boa divisão de atividades de processos computacionais para usufruir de uma comunicação entre diversos ambientes legados, capazes de controlar suas interações entre si, provendo um melhor benefício por seu uso paralelo. Como se pode visualizar esquematicamente através da Figura 1.

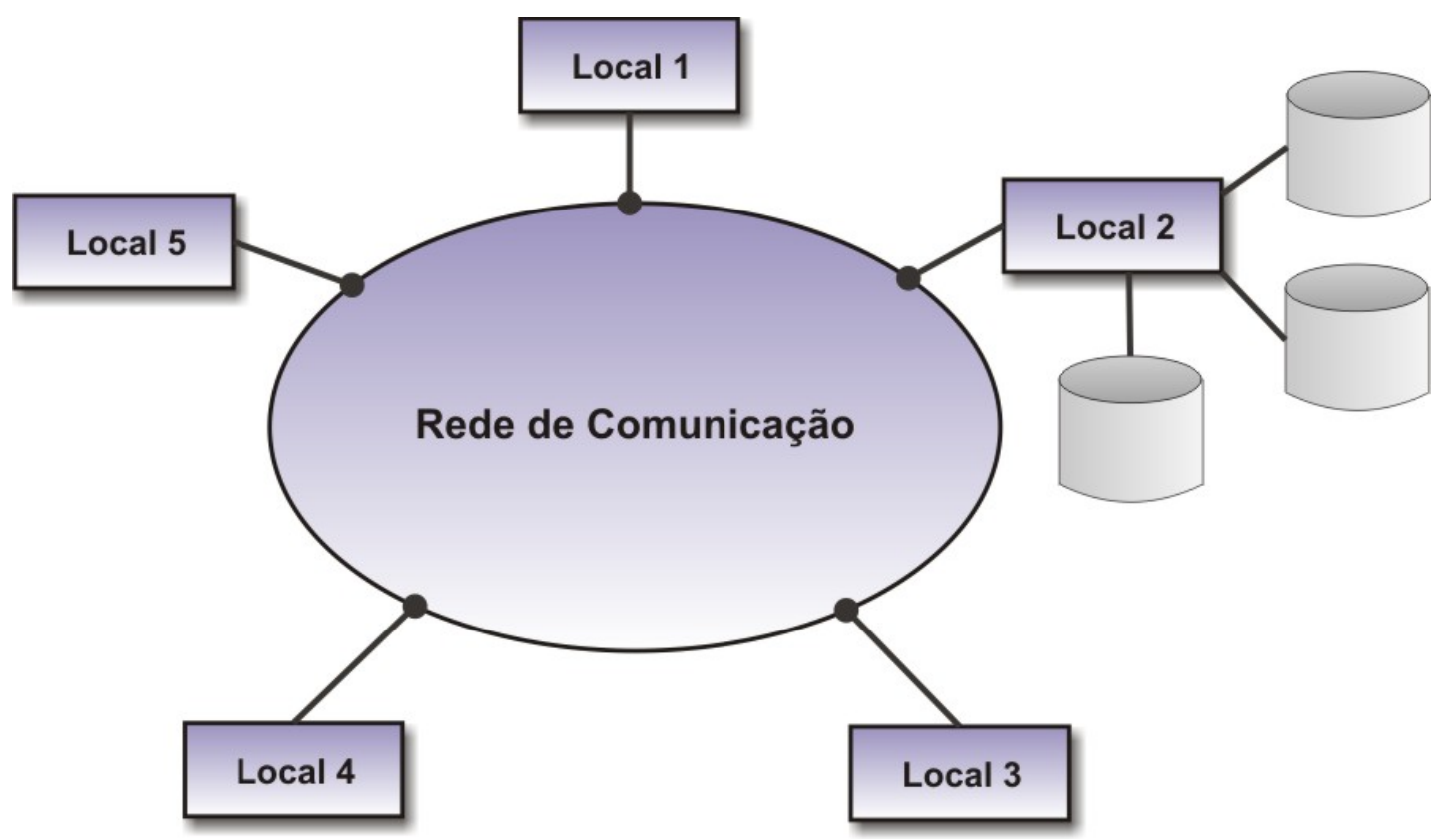

Figura 1 - Integração dos pontos distribuídos através da rede de computadores (baseado em figura de Ozsu e Valduriez, 1999).

Para o caso da área de biodiversidade, a necessidade do uso de bases de dados distribuídas é justificada pelo fato de as informações ficarem localizadas em diversos provedores espalhados pelo globo. Entretanto, o GBIF adota duas estratégias distintas para seus dados. A primeira consiste na aquisição dos dados dos provedores, na qual são utilizados protocolos e esquemas de dados criados para as necessidades de biodiversidade; já no segundo caso, os portais centralizadores fornecem serviços baseados em tecnologia UDDI, que fornecem informações já padronizadas em conformidade com as características do GBIF (UDDI, 2009) (GBIF, 2009).

O uso do padrão UDDI demonstra que é cogitado o uso mais amplo de Web services dentro de futuras versões dos portais e provedores. Segundo BOEYEN 
(2002), é possível conciliar níveis aceitáveis de segurança na implementação de Web services como ferramenta para transferência de dados.

A demanda por dados digitalizados de biodiversidade é dada pela grande quantidade de especialistas, que utilizam dessa informação para evolução de seus trabalhos (HOUSE, 2002). Muitas bibliotecas digitais voltadas à publicação de dados específicos como, por exemplo, CALFLORA (California Plants) que é uma biblioteca digital botânica fornece a seus usuários acesso via internet a seus portais, os quais contêm estas informações publicadas. No entanto, a forma e os interesses dos campos e detalhes da publicação variam e a forma e local da aquisição destas também. Esse fato, aliado à diversidade em si, gera a necessidade de padronização e é devido a essa necessidade que foi criado o esquema de dados conhecido como DarwinCore (DwC).

O esquema DwC é um padrão que visa a facilitar a troca de informações de ocorrências geográficas de espécimes em coleções (DWC, 2009).

Como a profundidade de informações necessárias varia, foram também desenhadas extensões de dados, as quais permitem oferecer maiores quantidades de informações além das usuais.

Os portais de biodiversidade usufruem desse esquema de dados (DwC) para facilitar suas trocas de informações, mas é de real necessidade que suas bases de dados centralizadas possuam uma modelagem conceitual, que suporte estes esquemas de dados, e que também os provedores possam interagir com este modelo de forma a compartilhar suas informações. Conforme Batini; Lenzerini e Navathe (1986), no processo de desenvolvimento do banco de dados, itens importantes como seu esquema conceitual determinam com qual amplitude o mesmo pode fornecer detalhes de uma determinada informação.

No uso de banco de dados distribuídos, esta importância se estende à integração com esses diferentes esquemas utilizados entre provedor e portal. Ainda, segundo Batini; Lenzerini e Navathe (1986), os bancos de dados distribuídos e os sistemas de gerenciamento de banco de dados distribuídos são classificados em duas principais categorias: homogêneos, todos envolvidos possuindo o mesmo modelo de dados, e heterogêneos, possuindo uma variedade de modelos entre os envolvidos. No caso entre portais e provedores de dados, a segunda categoria (heterogêneos) retrata sua realidade, sendo assim, a integração entre estes modelos é necessária. 


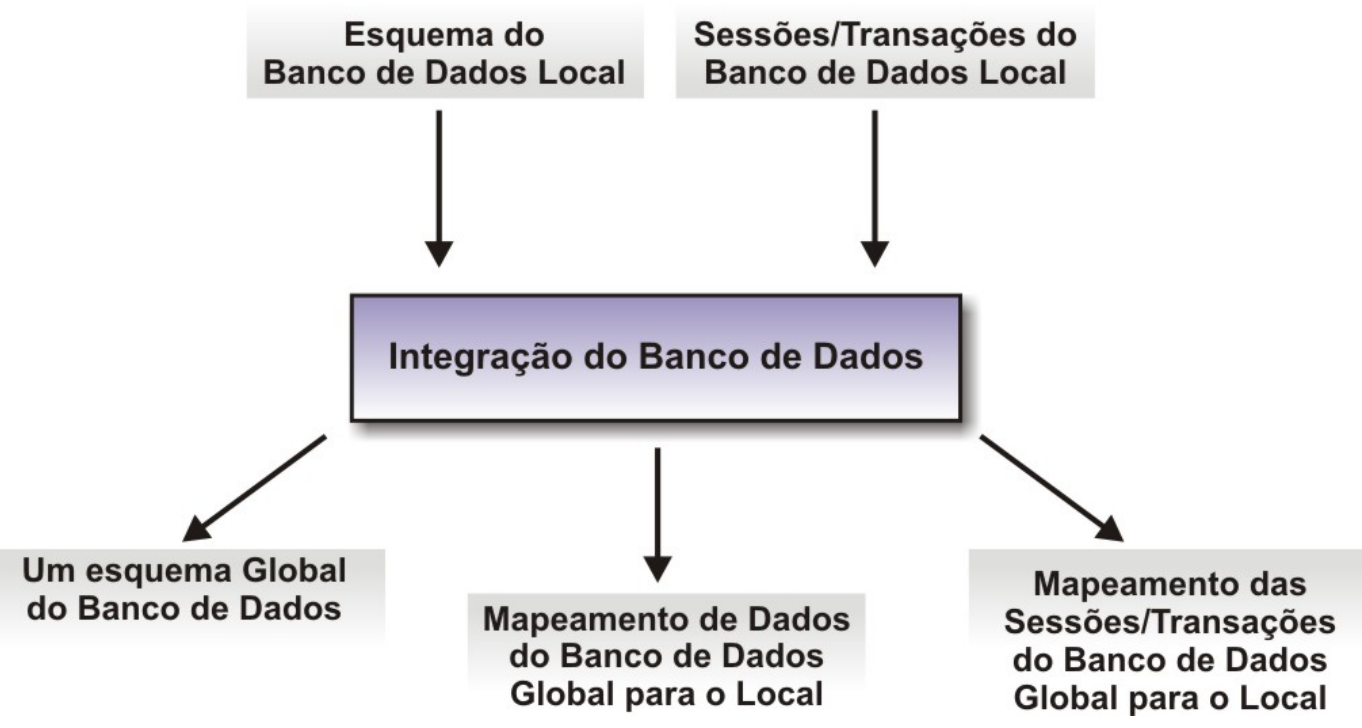

Figura 2 - Entradas e saídas de uma integração de banco de dados (baseado em figura de Batini; Lenzerini e Navathe, 1986)

Conforme pode-se notar na Figura 2, o papel do esquema global é de fornecer dados comuns entre as várias bases de dados envolvidas. Neste quesito, a solução utilizada pelo GBIF foi o esquema DwC; porém, o mesmo não assume esta integração nativa com uso de sistemas de gerenciamento de banco de dados distribuídos, pois a opção utilizada foi da replicação dos dados com uso de protocolos. Tirando assim, a necessidade de os formatos de banco de dados serem um grupo mais seleto e também, dos mesmos precisarem de maiores requisitos para fornecimento das informações (GBIF, 2009).

Além do DwC, outros esquemas foram apresentados anteriormente e posteriormente a este, sendo que alguns para finalidades diferentes, como é o caso do PlinianCore, que é utilizado para dados de espécies. Todos sempre se baseando no mesmo conceito de utilização, ou seja, a homogeneização dos dados.

Como resultado destas evoluções, foi proposto ao TDWG (Taxonomic Database Working Group), um esquema de dados que retratasse a interação entre ocorrências (DwC), as quais poderiam auxiliar em áreas de pesquisa como de polinizadores, em que tal informação é relevante a pesquisadores da área (INTERACTION EXTENSION, 2009). No entanto, essa replicação de dados requer integridade de dados, haja vista a necessidade de se utilizar como plano de referência a base de dados local dos portais. Segundo Ozsu e Valduriez (1999), manter integridade em bancos de dados distribuídos gera custos significativos aos 
recursos de sistema, porque as chaves conhecidas pelos gerenciadores locais devem ser restabelecidas na base de dados remota de destino. Assim sendo, a integridade é uma das etapas necessárias para concretização do processo de replicação de dados de interação de biodiversidade entre o provedor e o portal.

Para o transporte dos dados são utilizados protocolos específicos para biodiversidade, os quais têm como objetivo fornecer meios de comunicação entre os provedores e os portais, de forma que os dados possam ser replicados para uma base centralizadora (portal). Esta técnica é utilizada para que a velocidade de acesso e a disponibilidade dos dados sejam maiores; no entanto, isso requer procedimentos de atualização dos dados e, como citado anteriormente integridade dos mesmos, no caso do uso de esquema de interação.

\subsubsection{Protocolos para gerenciamento de réplicas}

Os esquemas de dados são referências lógicas, para que os dados transportados entre provedor e portal possam ser identificados e devidamente mapeados entre ambas as partes (DIGIR, 2009). No entanto, o processo é concretizado pelos protocolos de transporte. Estes, por sua vez, têm como objetivo transportar os dados (usando o esquema de dados como referência) entre as partes envolvidas. Para a integração entre portal e provedores de biodiversidade, foram desenvolvidas diversas soluções de transporte, entre as quais se destacam: DIGIR e TAPIR.

\subsubsection{Protocolo DiGIR}

O protocolo DiGIR foi desenvolvido com os objetivos (DIGIR, 2009) de:

- Ser capaz de receber dados estruturados de múltiplas bases de dados heterogêneas;

- Ser uma referência neste tipo de protocolo de dados.

As tecnologias de desenvolvimento foram baseadas em linguagens interpretadas para facilitar o seu uso em diversas plataformas, assim como uma ampla capacidade de comunicação com diferentes tipos de banco de dados. $O$ 
mesmo usufrui de um modelo de referência (esquema de dados), para fazer o mapeamento entre a base local onde foi instalado e o requisitante remoto (DIGIR, 2009).

Os protocolos (TAPIR e DiGIR) e os esquemas de dados (Ex: DwC e PlinianCore) não possuem dependências diretas entre si, pois ambos são isolados de forma a terem suas funções definidas e independentes, conforme a seguir:

- Esquema de dado: é utilizado para determinar quais campos e formatos de campos serão mapeados para o transporte. Podem ter extensões que permitem o uso de maior quantidade de campos para detalhar de forma mais ampla suas informações.

- Protocolo: Fornece meios, através do uso de rede de computadores, de receber solicitações de um requisitante e criar pacotes de dados padronizados (com o uso do esquema) para transmiti-los. Sua evolução requer compatibilidade entre as partes.

Baseado nestas divisões anteriormente citadas, foi desenhada (por GBIF, 2009) uma arquitetura abrangente, de forma a permitir a integração entre protocolo e diferentes versões de esquema. Pode-se ver na Figura 3, a seguir, a arquitetura estabelecida para o protocolo DiGIR. 


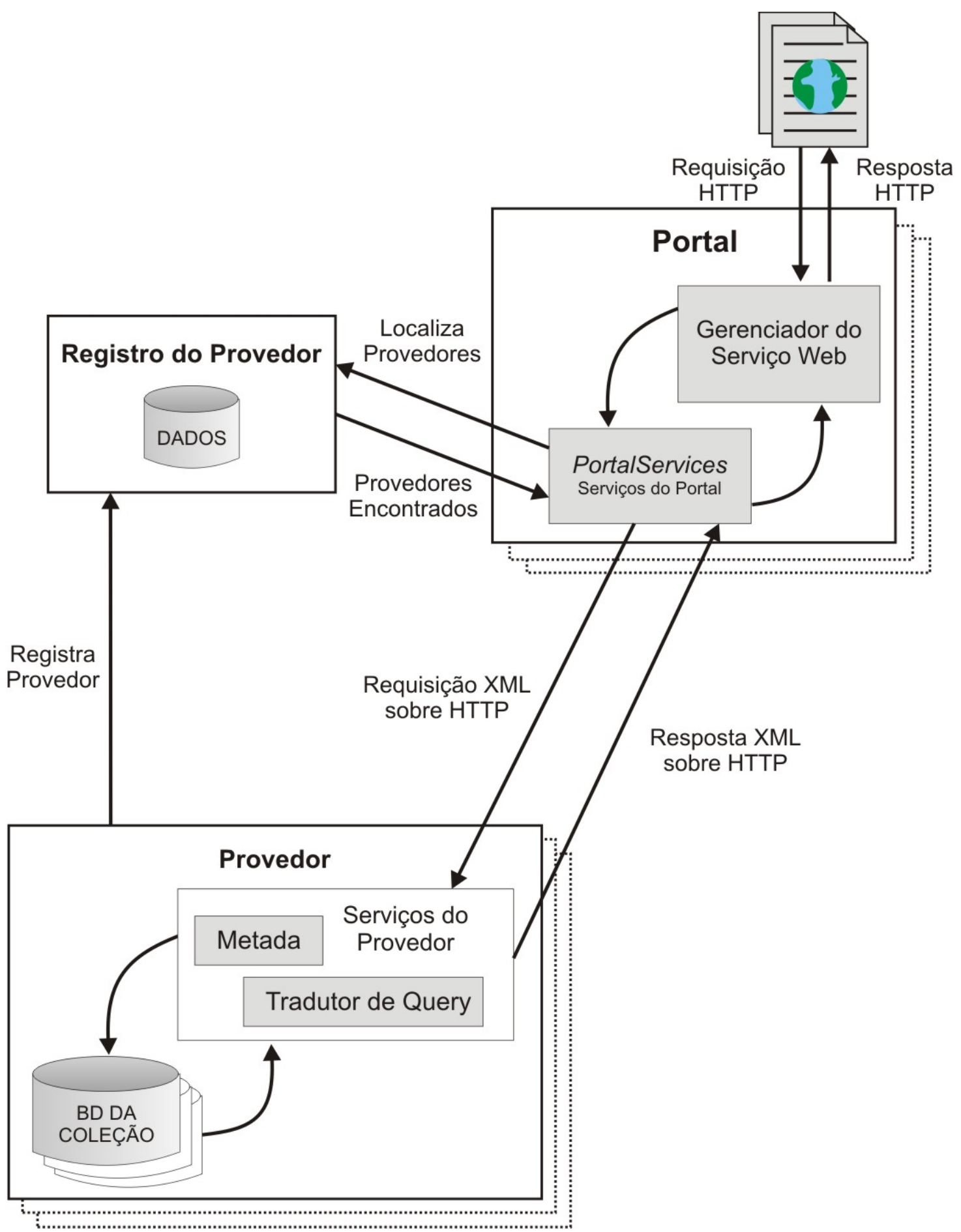

Figura 3 - Arquitetura de alto nível do DiGIR (baseada de DIGIR, 2009)

A linguagem de comunicação foi toda baseada em XML (eXtensible Markup Language), para facilitar tanto as solicitações como os retornos de dados. $O$ protocolo, sendo assim, é aplicado em ambos os cenários (provedor e portal), mas com enfoques diferentes.

No caso dos provedores os objetivos do DiGIR são mais específicos (DIGIR, 2009) para: 
- Efetuar a comunicação com a base de dados local;

- Fazer o mapeamento dos dados locais baseados no esquema utilizado (ex. DwC);

- Fornecer um serviço de requisição, para que portais ou outras ferramentas possam solicitar os dados disponíveis.

No que se refere aos portais, os objetivos do DiGIR (DIGIR, 2009) são:

- Fornecer as regras necessárias para formulação das requisições de dados;

- Retornar os dados em formato padronizado, baseado no esquema utilizado de forma que o portal possa interpretar e alocar estes dados em sua base de dados local.

\subsubsection{Protocolo TAPIR}

O TAPIR foi desenvolvido com objetivo similar ao DiGIR, ou seja, fornecer recursos para transporte de dados de base de dados heterogêneas. No entanto, o TAPIR combina os recursos e extensões tanto do DiGIR, como do protocolo BioCASE (outro protocolo de biodiversidade) criando uma comunicação mais otimizada, utilizando também da rede de computadores (BIOCASE, 2009) (TAPIR, 2009).

O domínio principal de uso para aplicação do TAPIR foi na área de biodiversidade; no entanto, assim como o DiGIR, pode atuar nas mais diversas áreas pela flexibilidade do uso do esquema de dados.

Os principais objetivos que efetivaram a criação do TAPIR (TAPIR, 2009) foram:

- Uso eficiente e de fácil entendimento;

- Sem vínculo a um específico sistema operacional;

- Sem vínculo a um específico esquema de dados;

- Sem vínculo a um específico modelo de saída de dados;

- Flexível e com possibilidade do uso de extensões;

- Compatível em desenvolvimento com outras ferramentas e recursos de trocas de dados;

- Gratuito e de uso livre. 
Para facilitar aos provedores, o TAPIR permite a criação de múltiplos recursos de dados, os quais podem conter informações diferenciadas e até mesmo esquema de dados diferenciados. Este benefício é amplamente utilizado no caso dos dados de interação, pois esses ficam geralmente em um único provedor, que fornece tanto os dados singulares, como os dados de interação (TAPIR, 2009).

A configuração desses protocolos exige certo conhecimentos técnicos, mas não muito profundos, até mesmo porque existem distribuições que permitem a instalação e publicação de forma rápida.

Uma vez operacional, o protocolo também fica aberto a requisições remotas, as quais podem solicitar, através de mensagens XML, dados singulares ou em maiores quantidades.

Pode-se ver, na Figura 4, um exemplo de requisição de dados usando TAPIR:

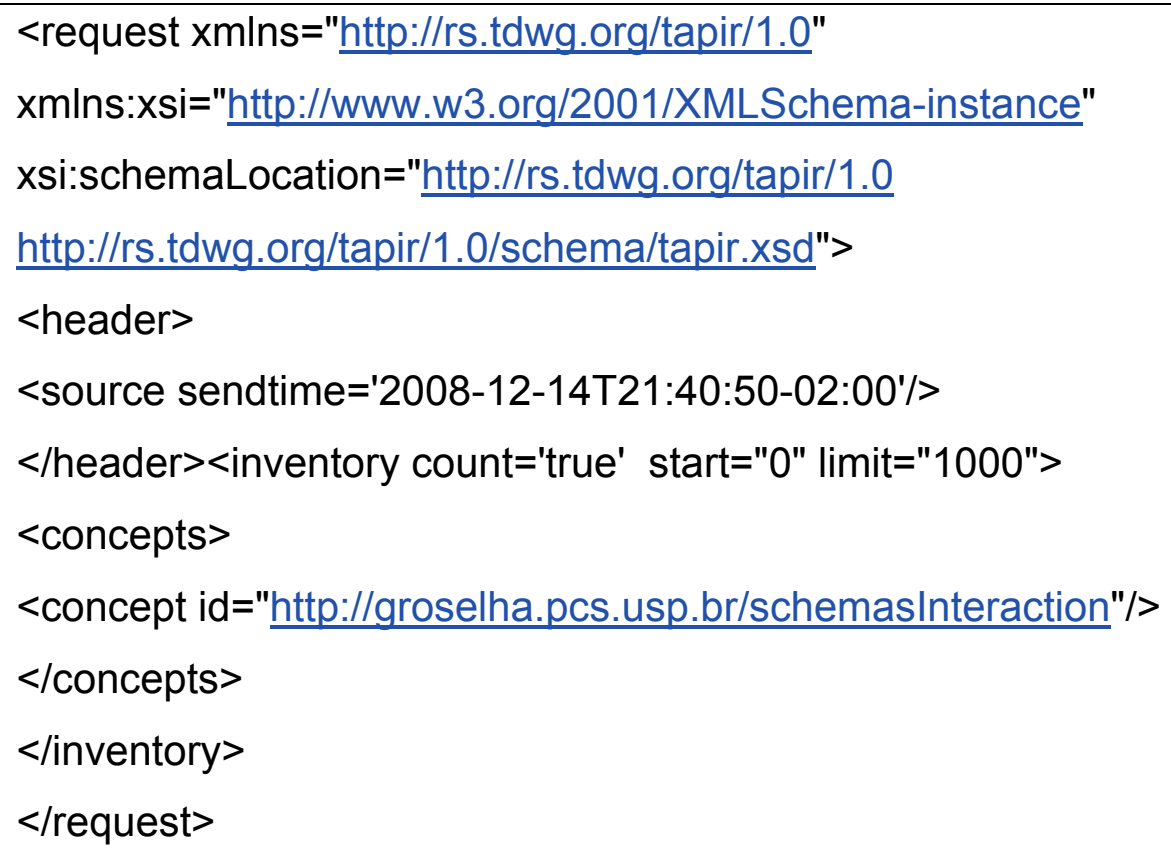

As requisições são processadas pelo protocolo baseado em seus vínculos com suas bases de dados locais e, através destes, são geradas as mensagens de saída. O requisitante indica diferentes comandos para obtenção de informações do provedor. Para a requisição anterior, a resposta seria de acordo com os dados existentes na base do provedor, conforme exemplo demonstrado na Figura 5. 


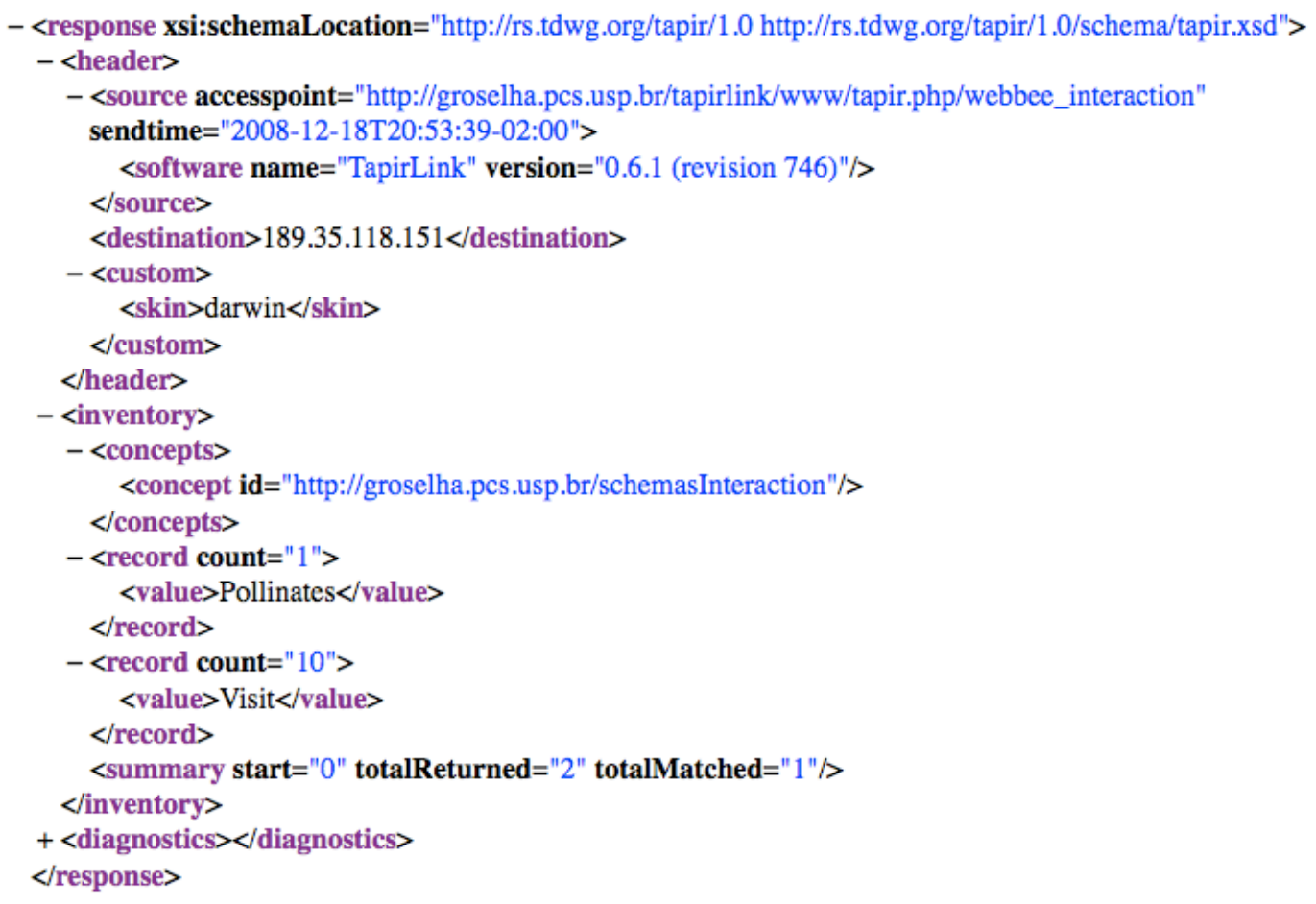

Figura 5 - Exemplo de mensagem de retorno usando TAPIR

Da mesma forma que no DiGIR, o protocolo TAPIR requer compatibilidade de versão de acordo com os recursos envolvidos. A abrangência, no que se refere a conexão com diferentes tipos de banco de dados e formatos, facilita a transformação de dados de biodiversidade, antes heterogêneos (no provedor), para dados homogêneos (no portal).

\subsection{Portal de Biodiversidade GBIF}

O GBIF é uma iniciativa internacional que tem como principal objetivo tornar os dados de biodiversidade acessíveis a todos os lugares do mundo. Para tornar possível este compartilhamento de dados, o portal fez uso de diversas tecnologias computacionais, de forma a possibilitar a coleta dos mesmos diretamente de seus provedores. Esse portal foi desenvolvido na linguagem Java e possui como principal característica o uso de frameworks como Spring e Hibernate, que proporcionam modularidade em seu código auxiliando em evoluções futuras, além de proporcionar uma boa prática de programação (JOHNSON, 2005). 


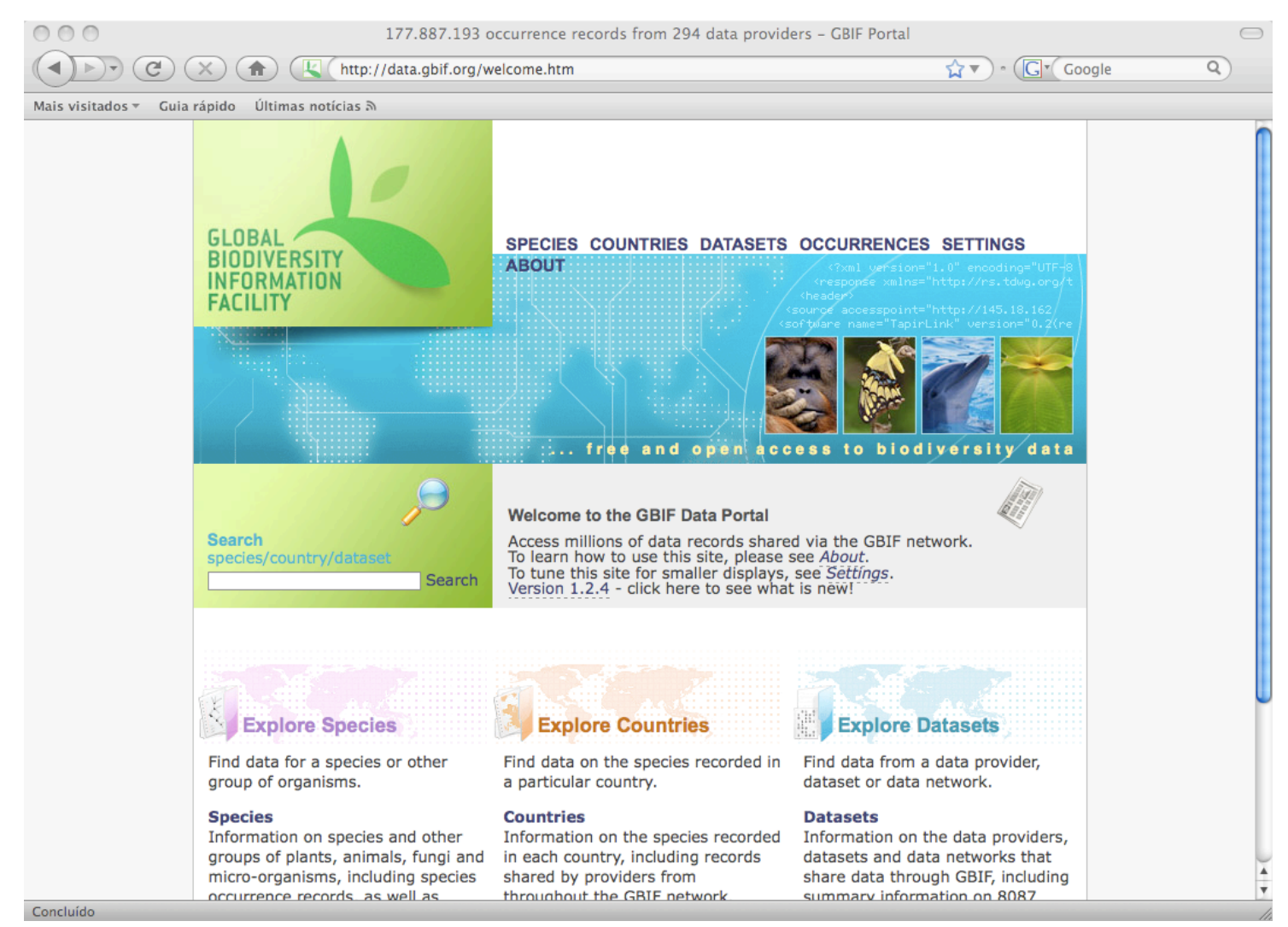

Figura 6 - Página principal do portal do GBIF (GBIF, 2009)

Com uma interface simples e objetiva, o portal GBIF como se pode ver na Figura 6, fornece como principais recursos disponíveis para os usuários finais (GBIF, 2009):

- Armazenamento centralizado de dados homogêneos de espécimes: baseados em campos específicos de biodiversidade (definido pelo padrão DwC), são armazenados registros provenientes de provedores, os quais ficam disponíveis a consulta no portal;

- Ferramenta de busca de ocorrências, datasets e países: Com filtros específicos, o usuário final pode optar por localizar registros de biodiversidade, por nome cientifico, família, pais ou até mesmo através do seu fornecedor original (provedor);

- Exploração da árvore taxonômica: Este recurso é uma forma rápida e padronizada de localização baseada na árvore taxonômica da espécie em questão;

- Exibição de posicionamento geo-referenciado: Alguns registros podem fornecer informações sobre a localidade de sua coleta, e nestes casos, o portal disponibiliza um mapa onde é exibida a localização ao usuário; 
- Suporte de múltiplos idiomas: Em razão de o acesso ao portal ser realizado por todo o mundo, este recurso possibilita aos pesquisadores escolherem o idioma disponível de sua preferência.

Conforme já aduzido, o código foi desenvolvido de forma modular, o que permite a sua reutilização para ampliação de recursos. Ao todo, o portal foi desenvolvido em 5 módulos, os quais possuem funcionalidades específicas, consoante breve descrição a seguir:

- portal-core: fornece os componentes de utilidades e tratamentos, utilizados pelos demais módulos;

- portal-index: este módulo faz toda a etapa de indexação e comunicação junto aos provedores, de forma a deixar os dados disponíveis para acesso pelas ferramentas do portal;

- portal-service: fornece os DAO (Data Access Objects) / DTO (Data Transfer Objects) e a integração direta com o Hibernate para acesso aos dados pelas ferramentas do portal;

- portal-web: contém toda a parte gráfica e visual do portal. É este módulo que gera o ambiente web, necessário para o acesso. Ele requer os demais módulos para funcionamento;

- portal-webservice: este módulo é responsável pelos recursos de extensão do portal, tornando possíveis integrações entre outras ferramentas específicas e transporte ordenado de dados.

Todos os módulos estão integrados e organizados através do framework Spring.

“... O Spring fornece uma solução leve para construir aplicativos
empresariais e, ao mesmo tempo, continuar a suportar a possibilidade do
uso do gerenciamento de transação de acesso remoto à sua lógica
utilizando serviços RMI (Remote Method Invocation) ou serviços Web,
recursos de envio de e-mail e várias opções para persistir seus dados em
um banco de dados. O Spring fornece uma estrutura MVC (Model View
Controller), maneiras transparentes de integrar AOP (Aspect Oriented
Programming) ao seu software e uma hierarquia bem estruturada de
exceções, incluindo mapeamento automático a partir das hierarquias de
exceções proprietárias.
O Spring, porém, pode ser o local ideal para todos seus aplicativos
corporativos; ele é modular, permitindo que você utilize partes dele, sem
adicionar as partes restantes..." (HEMRAJANI, 2006)

Dentro do portal GBIF, conforme segue a Figura 7, pode-se ver a organização MVC entre os diferentes componentes: 


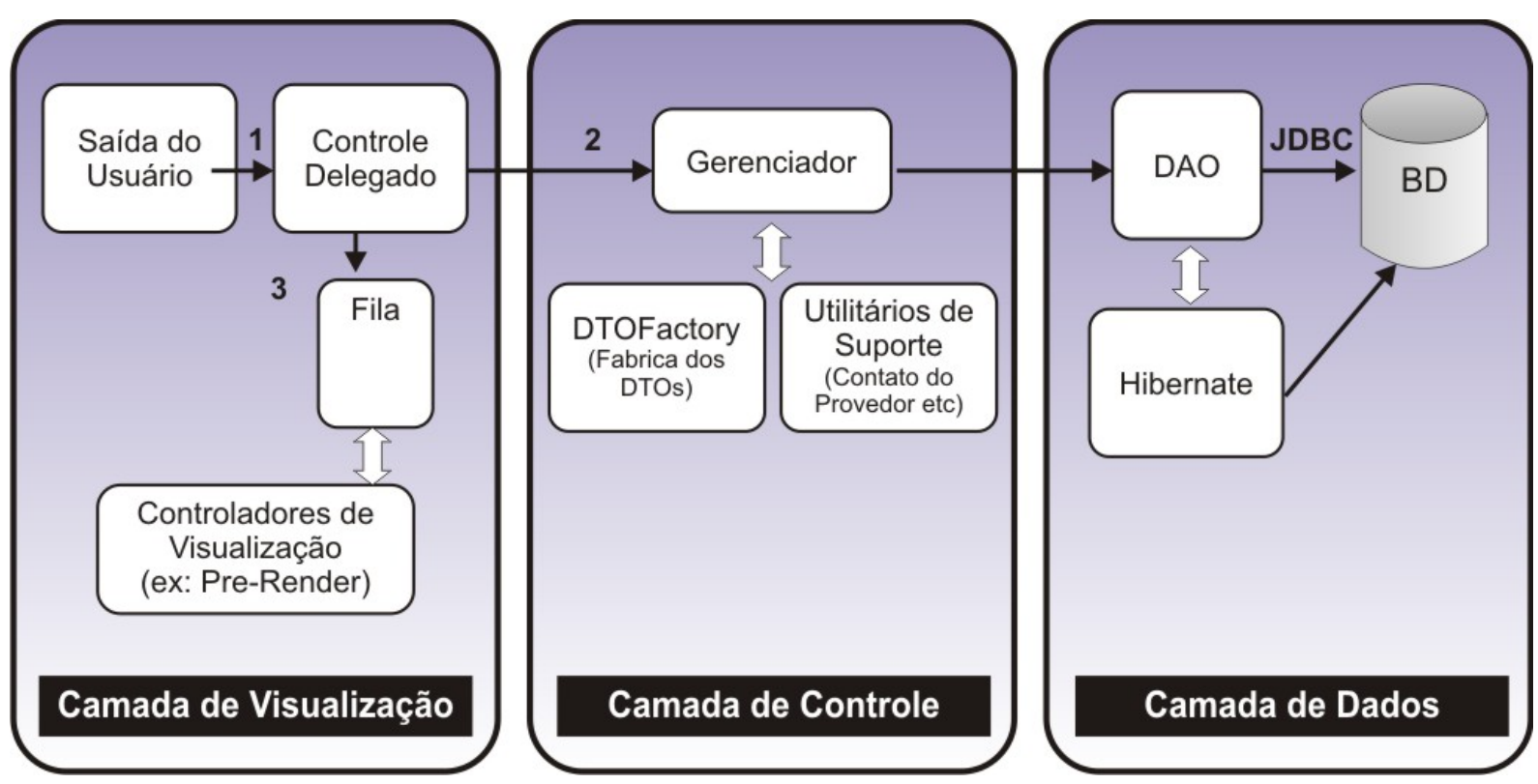

Figura 7 - Camada MVC utilizada pelos componentes do portal GBIF

\subsubsection{Replicação de dados}

Para a disponibilização dos dados no portal, é feito um processo de replicação de dados, que faz contato junto ao provedor e usufrui do esquema de dados e protocolo para trazer as informações junto à base de dados local.

O portal tem a capacidade de se comunicar com diversos provedores, mesmo com variedade de esquemas e protocolos. Seu processo de replicação envolve diversas etapas, conforme descrito a seguir (ver Apêndice B para maiores detalhes):

- Vinculação do provedor e seus dados de acesso: indica na base de dados do portal o novo provedor e seu URL (Uniform Resource Locator) de acesso, assim como qual protocolo e esquema de dados é utilizado para comunicação;

- Aquisição dos dados do provedor: É feito um contato inicial junto ao provedor, que repassa dados sobre os dados a serem fornecidos, itens como direitos autorais, instituição, entre outros;

- Criação de um inventário: através de um elemento chave (nome científico no caso do esquema (DwC) é realizada uma indexação dos registros, para facilitar no processo de requisição subsequente;

- Obtenção dos dados sem tratamento: são enviadas requisições para o provedor baseado no inventário criado e os dados são recebidos já 
localmente, porém sem nenhum tratamento diante da base relacional local utilizada;

- Extração dos dados: uma vez que os dados estejam disponíveis localmente, esta etapa do processo faz o tratamento dos dados de forma que fiquem otimizados para o acesso pelas ferramentas do portal (ex: busca de espécimes);

- Rotinas de estatísticas e fechamento: após o término da aquisição dos dados, algumas rotinas locais facilitam e otimizam as estatísticas de dados do portal, bem como a formação da árvore taxonômica.

Uma vez replicados na base local do portal, os dados podem ser atualizados; para isso, é utilizado como referência um campo que determina a data da última alteração de cada registro.

\subsection{Método para análise de desempenho}

Com a diversidade de modelos de transação atualmente existentes, a necessidade de adequação e otimização torna-se fundamental para viabilidade de processos longos. Segundo CORRÊA (2002), ao segmentar etapas de um processo longo, pode-se implantar neste métricas, as quais geram informações úteis para torná-lo mais otimizado. A referência utilizada neste estudo, para estabelecimento de métricas e elaboração da fórmula, se baseiam em um projeto de alocação definido por CORRÊA (2002), que leva em consideração a camada de aplicação do modelo OSI (Open System Interconnection), abstraindo as demais. 


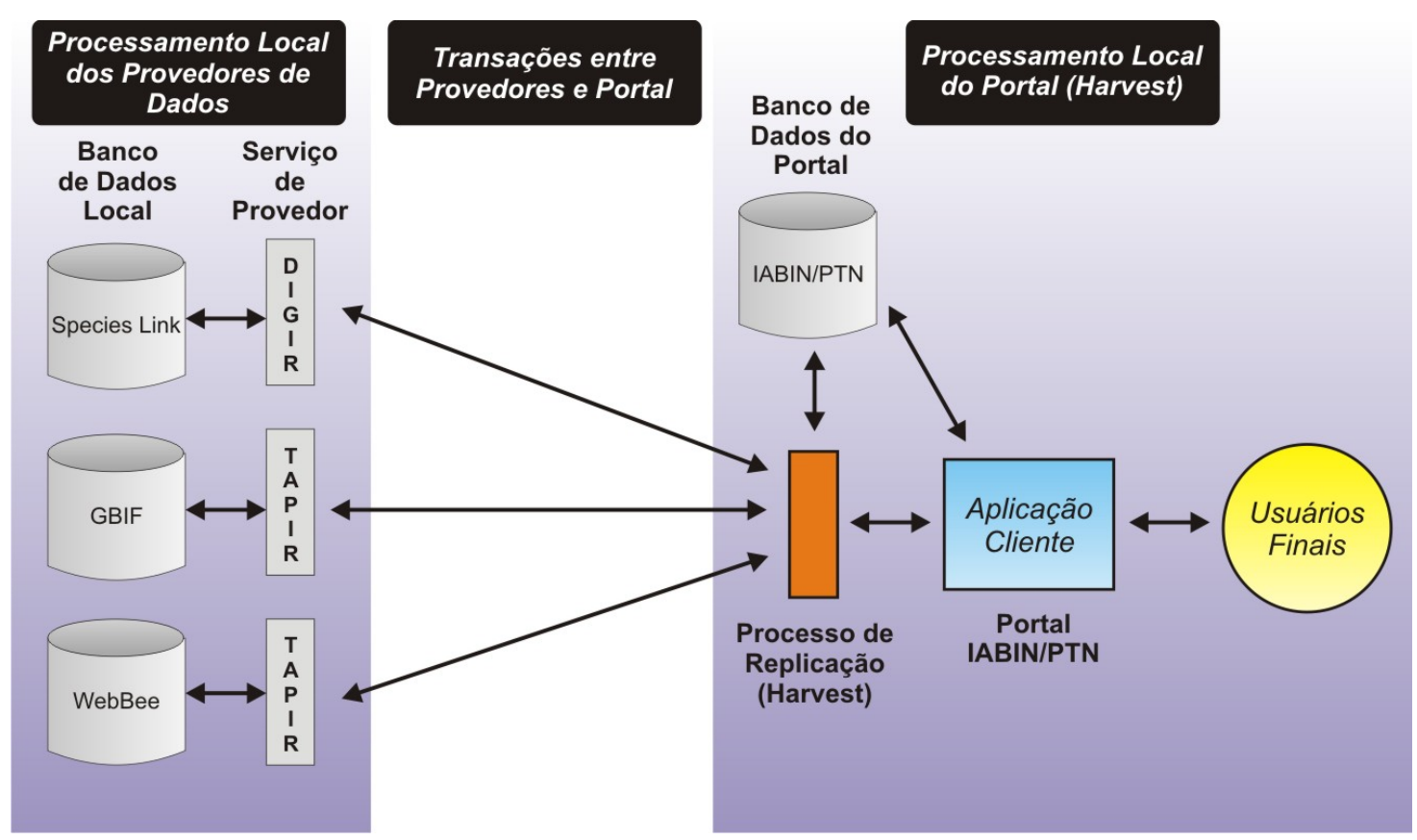

Figura 8 - Arquitetura proposta para o atual sistema TAPIR / DiGIR do portal de polinizadores

$\mathrm{Na}$ Figura 8, pode-se verificar que existem 3 etapas distintas a serem enquadradas nesse processo, que é conhecido como Harvest, sendo estas:

- Processamento local dos provedores de dados: Envolve o mapeamento dos campos da base de dados local para disponibilização dessa através do protocolo que fornecerá o serviço aos portais;

- Transações entre provedores e portal: Esta etapa está diretamente ligada aos processos de rede e encapsulamento de dados, onde é relevante o posicionamento físico e a banda disponível;

- Processo local do portal: Onde é realizada a coleta dos dados por parte do portal. Isto ocorre na interligação de todos os provedores e nesse ponto, é realizada a indexação e alocação dos dados de forma a replicar os dados de origem.

As atuais formas de operação, referentes a dados de biodiversidade, ainda possuem muitos pontos falhos que podem ser otimizados, principalmente na relação taxonômica e formatos de armazenamento dessa modalidade de informações (XU et al., 2002).

Visando à análise de banco de dados distribuídos, segundo CORRÊA (2002), os modelos de custos de alocação tratam do problema da alocação dos fragmentos aos nós, através de funções de custos, que avaliam qual a alocação ótima dos 
fragmentos, permitindo uma execução eficiente das transações que fazem parte das aplicações distribuídas.

Ainda segundo CORREAA (2002), os cenários similares ao proposto neste trabalho (com base de dados distribuídas) inviabilizam o uso de modelos mais completos, pois tornam o projeto de alocação altamente complexo; sendo assim, o uso de menor quantidade de fatores torna um projeto com essas características mais satisfatório.

\subsection{Considerações Finais}

As técnicas utilizadas pelos portais de biodiversidade, no que se refere à centralização de dados, foram elaboradas diante do cenário existente nos provedores, fornecendo dados heterogêneos, não somente em seu modelo lógico, como também em seu modelo físico. $O$ uso dos protocolos permite que essa comunicação ocorra de forma mais simples; no entanto, o formato não prevê o uso de dados de interação, o que possibilita trazer informações relevantes para, por exemplo, a área de polinizadores.

Outro ponto relevante é o tempo pelo qual o processo se estende, pois cada etapa conta com diversas sub-etapas, o que dificulta a determinação de métricas para otimizar o processo. Vários fatores podem contribuir para o tempo de replicação dos dados, tais como: overhead das mensagens, latência entre requisições, quantidade de registros por pacote, entre outros. Mas sem as devidas métricas é inviável determinar uma estratégia de melhoria dessa sistemática.

Com a análise de desempenho do processo, é possível determinar os custos das etapas, e assim, contribuir para futuras melhorias do processo. 


\section{MODELO PARA ANÁLISE DE DESEMPENHO}

Neste capítulo é apresentado o modelo a ser utilizado para simular o desempenho de um processo de replicação de dados. Inicialmente são explanados mais detalhadamente os testes realizados, e como foram obtidos os dados para a formulação deste modelo.

Para a realização dos testes foram necessários 3 cenários diferentes, os quais são detalhados a seguir:

- Cenário 1 - Local: Tanto o ambiente do portal como o ambiente do provedor ficaram no mesmo computador, eliminando assim o impacto da rede.

- Cenário 2 - Remoto (Brasil): O ambiente do provedor foi alocado em um servidor dentro do Brasil, incluindo o impacto da rede no processo.

- Cenário 3 - Remoto (Estados Unidos): O ambiente do provedor foi alocado em um servidor internacional, aumentando significativamente a latência dos pacotes.

Antes de apresentar as configurações utilizadas nos cenários, é necessário o entendimento sobre as etapas que compreendem a replicação dos dados (Harvest) entre o provedor e o portal. Pode-se visualizar melhor através da Figura 9:

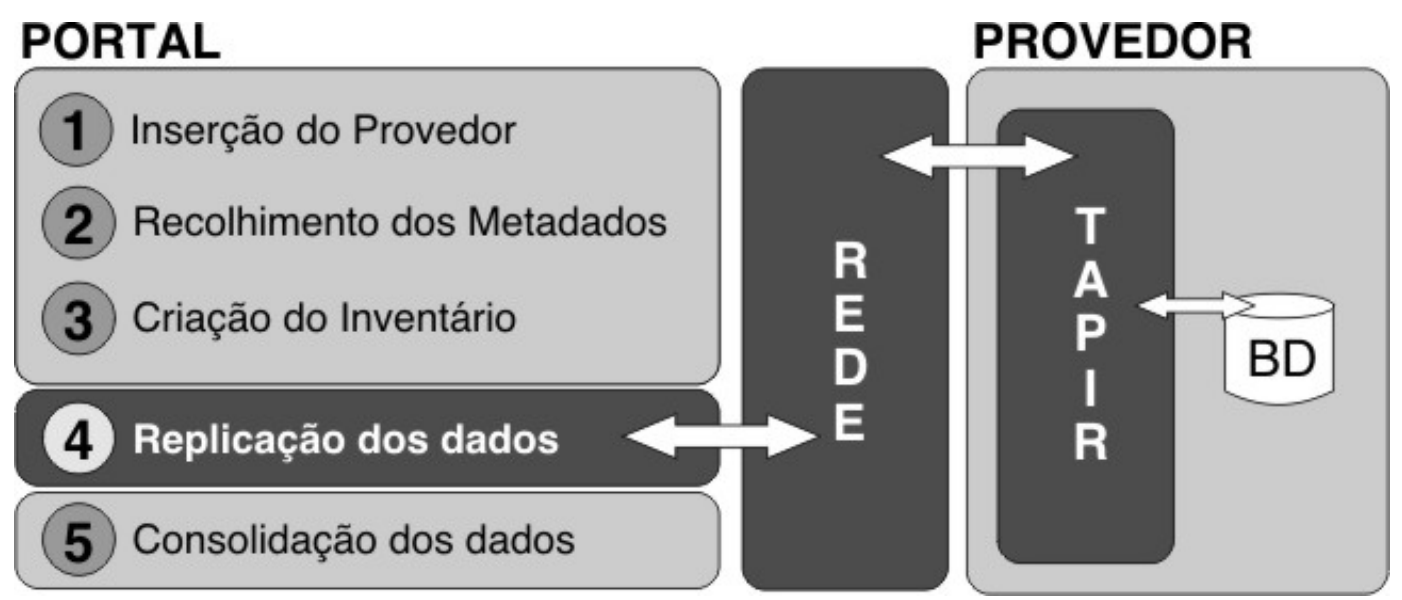

Figura 9 - Etapas do processo de replicação de dados entre provedor e o portal

Detalhando melhor:

- Inserção do Provedor no Portal (1): Dados iniciais, como o nome do provedor e a URL onde o servidor está localizado, devem ser inseridos no banco de dados. Neste ponto, não há necessidade de comunicação entre eles; 
- Recolhimento dos Metadados do Provedor (2): É feita uma comunicação inicial, que solicita ao provedor detalhes sobre suas características como provedor: Detalhes técnicos, Responsáveis pelo provedor, Recursos a serem disponibilizados, entre outros;

- Criação do Inventário (3): O portal solicita junto ao provedor a relação de inventário, baseado em nome cientifico, para dividir em partes as solicitações da próxima etapa. Este processo não demanda muito tempo, pois atua somente como um índice;

- Replicação dos dados do provedor para o portal (4): Este é o ponto mais importante do processo, pois é nele que os dados são efetivamente replicados do provedor para o portal. É esta etapa que este trabalho visa detalhar em termos de desempenho;

- Consolidação dos dados no portal (5): Uma vez transferidos, os dados devem se enquadrar com a base de dados relacional do portal. Esta etapa não necessita mais do acesso remoto ao provedor.

Esta dissertação visa analisar a etapa 4, a qual engloba uma atividade de acordo com a quantidade de registros a serem replicados. O objetivo principal é separar os custos (tempo de execução) do provedor, da rede e do portal.

\subsection{Criação das diferentes condições do processo}

Dentro de cada um dos 3 cenários anteriormente citados foram determinadas três variações de configurações, em busca de determinar diferentes condições no processo. Essas variações são aplicadas no provedor, no que se refere à quantidade de registros a serem trafegados por pacote. Pode-se modificar este parâmetro para a quantidade desejada, e para estes testes foram escolhidos: 50 , 200 e 400 registros por pacote.

Cada pacote de dado é um conteúdo XML com as informações, e quanto mais registros são agrupados, menor o número de pacotes necessários para o processo de replicação. Ao que, a princípio, pode parecer simples (usar o maior número possível) constatou-se que, dependendo da capacidade do computador utilizado, números grandes podem ter desempenho piores, como visto mais adiante. 
É possível visualizar, na Figura 10, o local onde podemos personalizar no provedor a quantidade de dados a serem utilizados por pacote:

\begin{tabular}{|l|l|}
\hline (*) Maximum element repetitions: \\
\hline (*) Maximum element levels: & Log only requests: \\
\hline (*) Equals operators are case sensitive: & accepted \\
\hline (*) & no \\
\hline
\end{tabular}

Figura 10 - Interface de configuração do provedor TAPIR

Durante a realização dos testes, foi constatada que a variação no número de registros por pacote tem impacto diferenciado, também pela diferença do desempenho do servidor utilizado para o provedor. E, durante as diferentes combinações, as quais foram utilizadas para chegar aos números aqui apresentados, verificou-se que o uso de mais de 400 registros por pacote foi ineficaz em certas configurações do provedor TAPIR, o que não tornava a fórmula criada correta em seus resultados. Para evitar esse erro, a faixa permitida no que se refere a número de registros por pacote foi fixada na faixa de 50 a 400 .

\subsection{Banco de dados de amostra e os pontos de notificação}

Para efeito de comparação, optou-se por montar uma base de dados única a ser utilizada em todos os cenários e monitorar a variação de registros em todas as situações. Esta base de dados foi derivada de uma extração feita no GBIF, a qual contava com mais de 800 mil registros. Como esta quantidade tornava inviável a duração de cada teste, foi realizada a extração de 88.491 registros desta base, os quais continham 26 campos devidamente preenchidos, incluindo dados georeferenciais.

Era de conhecimento inicial que a rede iria variar de teste para teste (exceto no cenário 1 , onde o provedor e portal se localizam no mesmo computador), e para determinar os custos de cada elemento do cenário foram realizadas inserções de pontos de notificação (PN) nos códigos, como pode-se ver de forma ilustrada na Figura 11: 


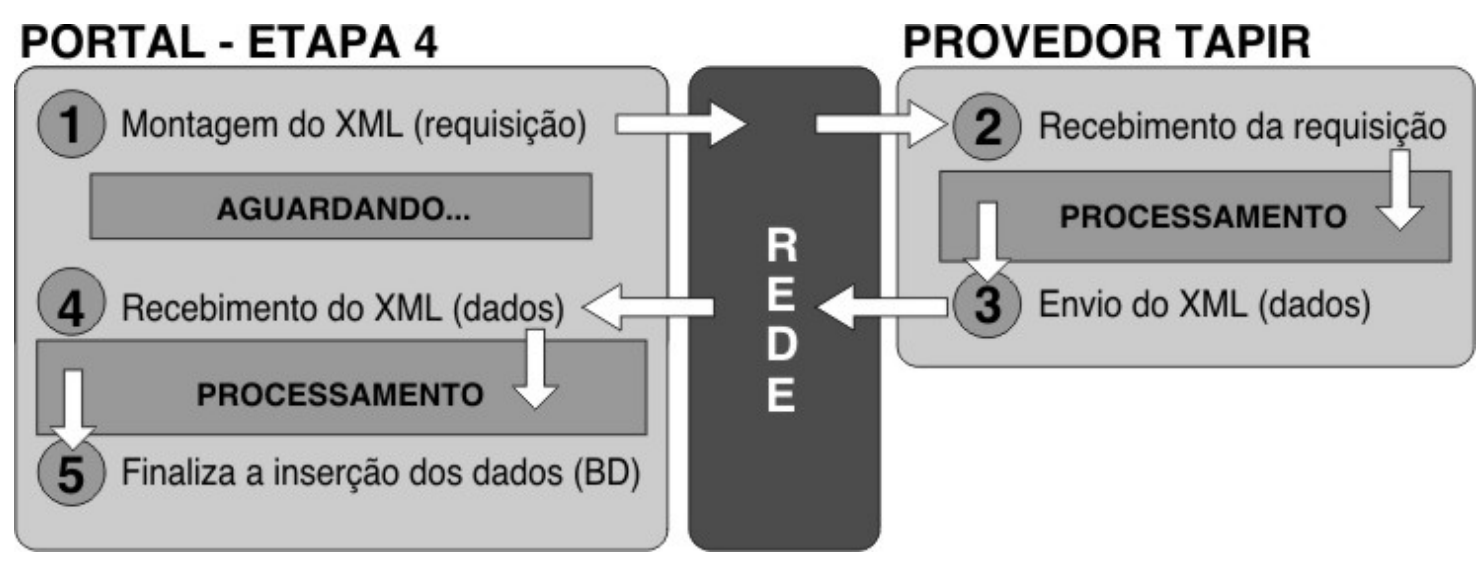

Figura 11 - Pontos de notificação nos códigos do portal e provedor

Detalhando melhor:

- PN 1 (portal) - Montagem do XML da requisição: Momento em que o portal irá começar a montar o XML para efetuar a requisição do pacote ao provedor.

- PN 2 (provedor) - Recebimento da requisição: Momento em que o provedor recebeu o pacote com a requisição do portal;

- PN 3 (provedor) - Envio do retorno ao portal: Momento em que o provedor já tem o pacote pronto e irá enviá-lo para o portal;

- PN 4 (portal) - Recebimento do retorno: Portal recebe o pacote de retorno com os dados para processar;

- PN 5 (portal) - Finaliza a inserção dos dados no banco: Momento em que o portal já efetuou o tratamento no pacote e inseriu os dados dentro de sua base de dados local.

\subsection{Execução dos testes e os resultados}

Para uma aferição coerente foram usados pontos de referência com horários ajustados de forma sincronizada, através de um único servidor de horário. As formas de coleta foram de acordo com as linguagens utilizadas em cada elemento, conforme descrição a seguir:

- No provedor TAPIR (Linguagem PHP): Foi usado um arquivo de texto simples temporário, onde de forma conjunta, os PN foram arquivados;

- No portal (Linguagem Java): Foi criada uma classe estática com uma lista, que arquivou na memória todas as informações, ao término estes dados foram transferidos para um arquivo de texto simples. 
Com os levantamentos referentes aos pontos de notificação foram gerados relatórios para cada cenário diferente em cada um dos elementos envolvidos (Provedor, Portal e Rede). Na Figura 12 pode-se ver os resultados no cenário 1 (local):

\section{ANÁLISE DO PROVEDOR}

\begin{tabular}{|c|c|c|c|c|}
\hline \multicolumn{5}{|c|}{ Local - 50 por pacote } \\
\hline 4,83 & 5,41 & 0,58 & & \\
\hline 6,16 & 6,72 & 0,56 & & \\
\hline 7,29 & 7,87 & 0,58 & Média & 0,586 \\
\hline 8,32 & 8,95 & 0,63 & RpS & 0,012 \\
\hline 9,39 & 9,97 & 0,58 & & \\
\hline \multicolumn{5}{|c|}{ Local - 200 por pacote } \\
\hline 34,9 & 36,8 & 1,92 & & \\
\hline 37,61 & 39,4 & 1,78 & & \\
\hline 40,16 & 42 & 1,79 & Média & 1,88 \\
\hline 42,75 & 44,5 & 1,77 & RpS & 0,009 \\
\hline 45,33 & 47,5 & 2,14 & & \\
\hline \multicolumn{5}{|c|}{ Local - $\mathbf{4 0 0}$ por pacote } \\
\hline 22,78 & 26,4 & 3,57 & & \\
\hline 30,77 & 34,4 & 3,6 & & \\
\hline 37,22 & 40,7 & 3,48 & Média & 3,56 \\
\hline 41,07 & 44,6 & 3,55 & RpS & 0,009 \\
\hline 47,12 & 50,7 & 3,6 & & \\
\hline
\end{tabular}

ANÁLISE PORTAL/REDE

\begin{tabular}{|lr|}
\hline \multicolumn{2}{|c|}{ Local - 50 por pacote } \\
Tempo Proc. Portal & 0,238 \\
Tempo Médio do Retorno XML & 0,711 \\
>> Tempo Proc. TAPIR & 0,586 \\
>> Consumo Banda/Rede/Prot & 0,125 \\
Total & 0,948 \\
\multicolumn{2}{|c}{ Local - 200 por pacote } \\
Tempo Proc. Portal \\
Tempo Médio do Retorno XML \\
>> Tempo Proc. TAPIR & 2,825 \\
>> Consumo Banda/Rede/Prot & 0,148 \\
Total & 2,853 \\
\multicolumn{2}{|c}{ Local - 400 por pacote } \\
Tempo Proc. Portal & 2,355 \\
Tempo Médio do Retorno XML & 3,564 \\
>> Tempo Proc. TAPIR & 3,56 \\
>> Consumo Banda/Rede/Prot & 0,004 \\
Total & 5,919 \\
\hline
\end{tabular}

RESUMO DA REDE

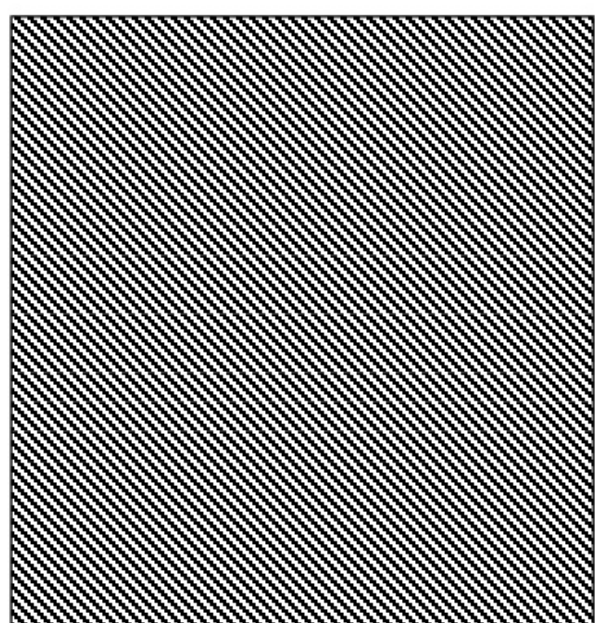

Figura 12 - Resultados da análise no cenário 1 (provedor local)

No primeiro quadrante (esquerda) tem-se a análise mais específica do provedor, na qual foram colocadas algumas amostras de dados de tempo (baseado nos quais formalizam a media obtida); dentro do quadrante temos 3 colunas à direita que são: Amostra PN2, Amostra PN3 e Diferença entre PN2 e PN3. Existem 3 segmentos que demonstram os resultados para os testes realizados com 50 registros por pacote, 200 registros por pacote ou 400 registros por pacote.

A média das diferenças das amostras resulta no tempo, em segundos, gasto para processar o pacote XML no provedor (entre PN2 e PN3). Nota-se que os números são maiores para quantidades maiores de registros por pacote, por isso foi extraído o que está nomeado como RpS (Registros por Segundo), que demonstra o tempo gasto para cada registro.

No segundo quadrante (central) temos a análise mesclada de portal e rede, na qual também temos resultados para cada quantidade de registros por pacote diferente. Todos os resultados são demonstrados em segundos e a descrição de cada:

- Tempo Proc. Portal: Refere-se a quanto tempo o portal (entre PN4 e PN5) demorou para processar um pacote; 
- Tempo Médio do Retorno XML: Este tempo engloba tanto a rede quanto o processamento do TAPIR (entre PN1 e PN4);

- Tempo Proc. TAPIR: Isoladamente quanto tempo foi gasto para o processamento no TAPIR (entre PN2 e PN3), obtido na primeira coluna;

- Consumo Banda/Rede/Protocolo: Foi considerado o tempo que faltou para completar o retorno do XML como tempo de rede.

No cenário 1, em que provedor e portal estavam alocados no mesmo servidor, foi possível constatar que os tempos de rede foram dados pelos tempos de processamentos mínimos do Apache (servidor do PHP) e do Tomcat (servidor do Java).

$\mathrm{Na}$ Figura 13 pode-se visualizar os resultados para o cenário 2 ,onde agora o provedor TAPIR se localiza em outro servidor (dentro do Brasil).

\section{ANÁLISE DO PROVEDOR}

\begin{tabular}{|c|c|c|c|c|}
\hline \multicolumn{5}{|c|}{ BR - 50 por pacote } \\
\hline 17,76 & 19,2 & 1,45 & & \\
\hline 20,49 & 21,9 & 1,45 & & \\
\hline 22,98 & 24,5 & 1,49 & Média & 1,458 \\
\hline 25,4 & 26,8 & 1,44 & RpS & 0,029 \\
\hline 27,88 & 29,3 & 1,46 & & \\
\hline \multicolumn{5}{|c|}{ BR - 200 por pacote } \\
\hline 7,47 & 12,3 & 4,86 & & \\
\hline 15,88 & 20,8 & 4,87 & & \\
\hline 23,76 & 28,7 & 4,91 & Média & 4,902 \\
\hline 31,14 & 36,1 & 4,98 & RpS & 0,025 \\
\hline 38,55 & 43,4 & 4,89 & & \\
\hline \multicolumn{5}{|c|}{ BR - 400 por pacote } \\
\hline 21 & 30,6 & 9,63 & & 0,024 \\
\hline 37,68 & 47,2 & 9,56 & & \\
\hline 52,89 & 62,4 & 9,5 & Média & 9,446 \\
\hline 0,22 & 9,39 & 9,17 & RpS & 0,024 \\
\hline 14,69 & 24,1 & 9,37 & & \\
\hline
\end{tabular}

\section{ANÁLISE PORTAL/REDE}

\begin{tabular}{|c|c|}
\hline \multicolumn{2}{|l|}{ BR - 50 por pacote } \\
\hline Tempo Proc. Portal & 0,238 \\
\hline Tempo Médio do Retorno XML & 2,143 \\
\hline$>>$ Tempo Proc. TAPIR & 1,458 \\
\hline >> Consumo Banda/Rede/Prot & 0,685 \\
\hline Total & 2,381 \\
\hline \multicolumn{2}{|l|}{ BR - 200 por pacote } \\
\hline Tempo Proc. Portal & 0,825 \\
\hline Tempo Médio do Retorno XML & 6,488 \\
\hline >> Tempo Proc. TAPIR & 4,902 \\
\hline >> Consumo Banda/Rede/Prot & 1,586 \\
\hline Total & 7,313 \\
\hline \multicolumn{2}{|l|}{ BR - 400 por pacote } \\
\hline Tempo Proc. Portal & 2,355 \\
\hline Tempo Médio do Retorno XML & 12,65 \\
\hline >> Tempo Proc. TAPIR & 9,446 \\
\hline >> Consumo Banda/Rede/Prot & 3,204 \\
\hline Total & 15,01 \\
\hline
\end{tabular}

\section{RESUMO DA REDE}

\begin{tabular}{|lr}
\hline \multicolumn{2}{|c}{ BR - 50 por pacote } \\
Tamanho Médio do Pacote (bytes) & 67463 \\
Latência Média Aferida (seg) & 0,023 \\
Tempo de Rede & 0,6846 \\
Tempo de Rede (sem latência) & 0,6616 \\
Velocidade (bytes $\times$ segundo) & 101969,47 \\
Velocidade (kbps) & $\mathbf{8 1 5 , 7 5 5 7}$ \\
\hline \multicolumn{2}{c}{ BR - 200 por pacote } \\
Tamanho Médio do Pacote (bytes) & 268191 \\
Latência Média Aferida (seg) & 0,023 \\
Tempo de Rede & 1,586 \\
Tempo de Rede (sem latência) & 1,563 \\
Velocidade (bytes $\times$ segundo) & 171587,33 \\
Velocidade (kbps) & $\mathbf{1 3 7 2 , 6 9 9}$ \\
\hline \multicolumn{2}{c}{ BR - 400 por pacote } \\
Tamanho Médio do Pacote (bytes) & 507410 \\
Latência Média Aferida (seg) & 0,023 \\
Tempo de Rede & 3,204 \\
Tempo de Rede (sem latência) & 3,181 \\
Velocidade (bytes $\times$ segundo) & 159512,73 \\
Velocidade (kbps) & $\mathbf{1 2 7 6 , 1 0 2}$ \\
\hline
\end{tabular}

Figura 13 - Resultados da análise no cenário 2 (provedor no Brasil)

Os dois quadrantes (esquerda e central) permanecem com os valores seguindo o mesmo padrão do cenário 1 , notam-se agora valores consideráveis no que se refere a consumo de rede (quadrante a direita). Adicionalmente, este relatório ganha uma terceira coluna, que detalha dados pertinentes à rede, considerando os dados a seguir:

- Tamanho médio do pacote (em bytes): No PN4 foi também armazenado o tamanho do pacote trafegado e, nos resultados, foram calculados o tamanho médio em bytes dos pacotes de retorno; 
- Latência média aferida (em segundos): Com ferramentas computacionais como iPerf ${ }^{2}$ foram realizados testes para detectar a latência de rede entre o provedor e o portal;

- Tempo de rede: Dado em segundos este campo é baseado no valor já obtido através da segunda coluna;

- Tempo de rede (sem latência): É subtraída aqui a latência para determinar somente o tempo gasto com a transmissão dos dados;

- Velocidade (bytes por segundo): Através da divisão entre o tamanho médio do pacote de dados e do tempo percorrido foi possível determinar qual a taxa de bytes trafegados por segundo.

- Velocidade (kbps): Com o dado de bytes por segundo foi convertido o valor para kbps (kilobits por segundo), padrão mais utilizado para determinar a velocidade no uso de redes de computadores.

Em um último cenário foram realizados testes em um servidor localizado nos EUA (Estados Unidos da America), e através da Figura 14 pode-se ver os resultados obtidos:

\section{ANÁLISE DO PROVEDOR}

\begin{tabular}{|c|c|c|c|c|}
\hline \multicolumn{5}{|c|}{ US - $\mathbf{5 0}$ por pacote } \\
\hline 27,98 & 28,5 & 0,56 & & \\
\hline 30,83 & 31,4 & 0,56 & & \\
\hline 33,45 & 34 & 0,56 & Média & 0,562 \\
\hline 36,04 & 36,6 & 0,57 & RpS & 0,011 \\
\hline 38,64 & 39,2 & 0,56 & & \\
\hline \multicolumn{5}{|c|}{ US - $\mathbf{2 0 0}$ por pacote } \\
\hline 23,41 & 25,2 & 1,8 & & \\
\hline 28,58 & 30,4 & 1,8 & & \\
\hline 34,1 & 35,9 & 1,8 & Média & 1,8 \\
\hline 39,29 & 41,1 & 1,8 & RpS & 0,009 \\
\hline 44,57 & 46,4 & 1,8 & & \\
\hline \multicolumn{5}{|c|}{ US - 400 por pacote } \\
\hline 0,71 & 4,35 & 3,64 & & \\
\hline 11,62 & 15,3 & 3,66 & & \\
\hline 21,27 & 23,2 & 1,93 & Média & 3,3 \\
\hline 26,75 & 30,4 & 3,64 & RpS & 0,008 \\
\hline 35,86 & 39,5 & 3,63 & & \\
\hline
\end{tabular}

\section{ANÁLISE PORTAL/REDE}

\begin{tabular}{|lr|}
\hline \multicolumn{2}{|c|}{ US - 50 por pacote } \\
Tempo Proc. Portal & 0,238 \\
Tempo Médio do Retorno XML & 2,197 \\
>> Tempo Proc. TAPIR & 0,562 \\
>> Consumo Banda/Rede/Prot & 1,635 \\
Total & 2,435 \\
\multicolumn{2}{|c}{ US - 200 por pacote } \\
Tempo Proc. Portal & 0,825 \\
Tempo Médio do Retorno XML & 4,444 \\
>> Tempo Proc. TAPIR & 1,8 \\
>> Consumo Banda/Rede/Prot & 2,644 \\
Total & 5,269 \\
\multicolumn{2}{|c}{ US - 400 por pacote } \\
Tempo Proc. Portal \\
Tempo Médio do Retorno XML \\
>> Tempo Proc. TAPIR \\
>> Consumo Banda/Rede/Prot & 3,355 \\
Total & 3,404 \\
& 9,059 \\
\hline
\end{tabular}

\section{RESUMO DA REDE}

\begin{tabular}{|lr|}
\hline \multicolumn{2}{|c|}{ US - S0 por pacote } \\
Tamanho Médio do Pacote (bytes) & 67463 \\
Latência Média Aferida (seg) & 0,169 \\
Tempo de Rede & 1,635 \\
Tempo de Rede (sem latência) & 1,466 \\
Velocidade (bytes x segundo) & 46018,417 \\
Velocidade (kbps) & $\mathbf{3 6 8 , 1 4 7 3}$ \\
\hline \multicolumn{2}{|c|}{ US - 200 por pacote } \\
Tamanho Médio do Pacote (bytes) & 268191 \\
Latência Média Aferida (seg) & 0,169 \\
Tempo de Rede & 2,644 \\
Tempo de Rede (sem latência) & 2,475 \\
Velocidade (bytes $\times$ segundo) & 108360 \\
Velocidade (kbps) & $\mathbf{8 6 6 , 8 8}$ \\
\hline \multicolumn{2}{|c|}{ US - 400 por pacote } \\
Tamanho Médio do Pacote (bytes) & 507410 \\
Latência Média Aferida (seg) & 0,169 \\
Tempo de Rede & 3,404 \\
Tempo de Rede (sem latência) & 3,235 \\
Velocidade (bytes $\times$ segundo) & 156850,08 \\
Velocidade (kbps) & $\mathbf{1 2 5 4 , 8 0 1}$ \\
\hline
\end{tabular}

Figura 14 - Resultados da análise no cenário 3 (provedor internacional)

Os resultados diferem por questões basicamente de rede e também da configuração do servidor utilizado no provedor (que variou de teste para teste). Com os resultados separados, foi possível constatar que o desempenho deste servidor

\footnotetext{
${ }^{2}$ Ferramenta para análise de rede - versão 1.7 .0 (http://www.noc.ucf.edu/Tools/lperf/)
} 
interfere no tempo do processo e por isso, o mesmo foi considerado no modelo proposto. Segue a relação dos equipamentos utilizados em cada cenário:

- Portal (cenário 1, 2 e 3): Processador Core 2 Duo 2.33ghz, 4GB de RAM e 4655,03 bogomips (conforme informação do Linux)

- Provedor (cenário 1): Mesma configuração do portal.

- Provedor (cenário 2): Processador Athlon XP 2200+ 1,4Ghz, 512Mb de RAM e 2726,08 bogomips (conforme informação do Linux)

- Provedor (cenário 3): Processador Intel Xeon Dual Core 2,4Ghz, 2GB de RAM e 4788,58 bogomips (conforme informação do Linux).

Com estes mesmos resultados, determinando as constantes e as variáveis, foi possível elaborar o modelo proposto. A Tabela 1 demonstra as constantes e suas respectivas origens:

Tabela 1 - As constantes utilizadas nas formulas e suas origens.

\begin{tabular}{|c|c|c|c|}
\hline $\begin{array}{l}\text { Nome na } \\
\text { Fórmula }\end{array}$ & Valor & Descrição & Como foi obtida: \\
\hline $\begin{array}{l}\text { CRP (em } \\
\text { segundos) }\end{array}$ & 0,00492 & $\begin{array}{lr}\text { Custo por } \\
\text { Registro no } \\
\text { Portal }\end{array}$ & $\begin{array}{l}\text { Através da média de tempo gasto no } \\
\text { portal, assumindo o custo por registro } \\
\text { individual }\end{array}$ \\
\hline $\begin{array}{l}\text { CRPT (em } \\
\text { segundos) }\end{array}$ & 0,003 & $\begin{array}{l}\text { Custo por } \\
\text { Ponto de } \\
\text { Desempenho } \\
\text { por Registro } \\
\text { no Provedor }\end{array}$ & $\begin{array}{l}\text { O provedor TAPIR foi implantado em } \\
\text { diferentes configurações e foi } \\
\text { exaustivamente verificado seu } \\
\text { comportamento, sendo possível } \\
\text { elaborar uma relação de pontos para } \\
\text { determinar o tempo de processamento } \\
\text { médio. }\end{array}$ \\
\hline $\begin{array}{l}\text { TR (em } \\
\text { bytes) }\end{array}$ & 52,2 & $\begin{array}{l}\text { Tamanho } \\
\text { Médio por } \\
\text { campo } \\
\text { mapeado }\end{array}$ & $\begin{array}{l}\text { Como cada provedor TAPIR pode ser } \\
\text { configurado de forma diferente foi } \\
\text { verificado que a melhor forma de obter } \\
\text { o tamanho médio do pacote de dados é } \\
\text { baseando-se na quantidade de campos } \\
\text { mapeados. Foi obtido da média de } \\
\text { tamanho de cada campo no XML. }\end{array}$ \\
\hline
\end{tabular}


Para efetivação dos cálculos é necessário preencher os dados variáveis da fórmula que tornam possível simular o custo total do processo de replicação de dados. Através da Tabela 2 podemos verificar os campos envolvidos e seus respectivos papéis na fórmula proposta.

Tabela 2 - Campos variáveis envolvidos nas fórmulas

\begin{tabular}{|c|c|c|}
\hline $\begin{array}{l}\text { Nome na } \\
\text { Fórmula }\end{array}$ & Descrição & Entradas válidas \\
\hline nreg & $\begin{array}{l}\text { Número de registros por pacote: } \\
\text { Determina quantos registros } \\
\text { serão trafegados em cada } \\
\text { pacote de informação. }\end{array}$ & entre 50 e 400 \\
\hline $\mathrm{fd}$ & $\begin{array}{l}\text { Fator de } \\
\text { Determina qual é o nível de } \\
\text { processamento do provedor } \\
\text { TAPIR. }\end{array}$ & $\begin{array}{l}\text { Entre } 1 \text { e 10: } \\
\text { 1-3: Xeon 3-4Gb de RAM } \\
\text { 4-6: Intel Core } 2 \text { Duo 2Gb de RAM } \\
\text { 6-8: Athlon/Dual Core 1GB de RAM } \\
\text { acima de 9: Computadores inferiores } \\
\text { (não aferidos neste trabalho) }\end{array}$ \\
\hline qcampos & $\begin{array}{l}\text { Quantidade de campos } \\
\text { mapeados no provedor TAPIR }\end{array}$ & $\begin{array}{l}\text { Maior que 20. A que abrange a } \\
\text { maioria dos casos. Números } \\
\text { menores podem distorcer os } \\
\text { resultados, pois a media de espaço } \\
\text { usado por campos pode ser } \\
\text { desbalanceada. }\end{array}$ \\
\hline lat & $\begin{array}{l}\text { Latência média entre as partes } \\
\text { (provedor e portal). O impacto } \\
\text { deste campo não é tão grande, } \\
\text { exceto em provedores } \\
\text { internacionais. }\end{array}$ & Sem limitações \\
\hline totreg & $\begin{array}{l}\text { Quantidade total de registros a } \\
\text { serem efetuadas a replicação } \\
\text { de dados }\end{array}$ & Sem limitações \\
\hline
\end{tabular}

continua 
conclusão

\begin{tabular}{|l|l|l|}
\hline $\begin{array}{l}\text { Nome na } \\
\text { Fórmula }\end{array}$ & \multicolumn{1}{|c|}{ Descrição } & \multicolumn{1}{|c|}{ Entradas válidas } \\
\hline banda & $\begin{array}{l}\text { Velocidade medida em bits por } \\
\text { segundo }\end{array}$ & Sem limitações \\
\hline
\end{tabular}

Seguem as fórmulas de apoio com seus respectivos descritivos na Tabela 3:

Tabela 3 - Fórmulas de apoio para o modelo matemático

\begin{tabular}{|l|l|}
\hline \multicolumn{1}{|c|}{ Fórmula } & $\begin{array}{l}\text { Descrição } \\
\text { segundos) }\end{array}$ \\
\hline$C P P_{p a}=n r e g * C R P$ & $\begin{array}{l}\text { Determina o custo do provedor TAPIR por } \\
\text { pacote (em segundos) }\end{array}$ \\
\hline$T P_{p a}=n$ campos $^{*} T R^{*}$ *areg & $\begin{array}{l}\text { Determina o tamanho médio de um pacote } \\
\text { de dados (em bytes) }\end{array}$ \\
\hline$V M R=\frac{\text { banda }}{8}$ & $\begin{array}{l}\text { Determina a velocidade média da rede (em } \\
\text { bytes por segundo) }\end{array}$ \\
\hline$C R_{p a}=$ lat $+\frac{T P}{V M R}$ & $\begin{array}{l}\text { Determina o custo da rede por pacote de } \\
\text { dados (em segundos) }\end{array}$ \\
\hline$Q M P=\frac{\text { totreg }}{n r e g}$ & $\begin{array}{l}\text { Determina a quantidade média de pacotes } \\
\text { a serem trafegados }\end{array}$ \\
\hline
\end{tabular}

E então, a fórmula final que determina o tempo total previsto para todo 0 processo de replicação de dados:

$C F=\sum^{Q M P}\left(C P_{p a}+C R_{p a}+C P T_{p a}\right)$

As variáveis que constam na fórmula (1) são:

- CF: Custo final da replicação (em segundos)

- QMP: Quantidade média de pacotes (em unidades)

- CP: Custo do portal por pacote (em segundos)

- CR: Custo da rede por pacote (em segundos) 
- CPT: Custo do provedor TAPIR por pacote (em segundos)

\subsection{Considerações finais}

O modelo proposto, teve como objetivo, abranger todos os itens pertinentes envolvendo a replicação de dados entre o provedor e o portal; no entanto, torna-se inviável inserir grandes quantidades de variáveis que podem ser de difícil obtenção (para um usuário). Sendo assim, foram utilizados somente os fatores que têm grande contribuição para o custo envolvido em cada etapa do processo.

Com intuito de comprovar a viabilidade da fórmula, foram feitas as comparações dos resultados reais com os resultados obtidos através da fórmula para os quatro testes cenários realizados com portal e provedor em servidores dedicados. Os resultados podem ser vistos através da Tabela 4.

Tabela 4 - Comparativo de resultados reais e obtidos através do modelo matemático

\begin{tabular}{|l|l|l|l|}
\hline \multicolumn{1}{|c|}{ Cenário } & $\begin{array}{c}\text { Tempo real } \\
\text { (em segundos) }\end{array}$ & $\begin{array}{c}\text { Tempo obtido pela } \\
\text { fórmula (em segundos) }\end{array}$ & Variação \\
\hline $\begin{array}{l}\text { Brasil }- \text { com } 50 \\
\text { registros por pacote }\end{array}$ & 3991 & 3750 & $-6,04 \%$ \\
\hline $\begin{array}{l}\text { Brasil - com 200 } \\
\text { registros por pacote }\end{array}$ & 3166 & 3253 & $+2,75 \%$ \\
\hline $\begin{array}{l}\text { Brasil com 400 registros } \\
\text { por pacote }\end{array}$ & 3145 & 3299 & $+4,90 \%$ \\
\hline $\begin{array}{l}\text { EUA - com 50 registros } \\
\text { por pacote }\end{array}$ & 4300 & 4080 & $-5,12 \%$ \\
\hline $\begin{array}{l}\text { EUA - com 200 } \\
\text { registros por pacote }\end{array}$ & 2307 & 2390 & $+3,60 \%$ \\
\hline $\begin{array}{l}\text { EUA com 400 registros } \\
\text { por pacote }\end{array}$ & 1983 & 2017 & $+1,71 \%$ \\
\hline
\end{tabular}

Como pode-se notar as variações chegam em um máximo de 6,04\%, valor o qual pode ser considerado aceitável dado o tempo final de sua realização. 


\section{ESTUDO DE CASO}

A IABIN, em conjunto com o LAA (Laboratório de Automação Agrícola) vem desde 2005 desenvolvendo um projeto de uma rede temática de polinizadores das Américas. Esse projeto inclui o desenvolvimento de um portal (baseado na tecnologia do GBIF) centralizando dados de diversas instituições, seguindo o uso do protocolo TAPIR com esquema de dados DwC e um novo esquema exclusivo para dados de interação.

Com o objetivo de demonstrar a aplicação do modelo deste trabalho, foi selecionada a replicação de uma base de dados real para efeito de comparação, baseada nas fórmulas já apresentadas. A base de dados escolhida foi a CEPANN do IBUSP (Instituto de Biociências da USP), mais especificamente do Laboratório de Abelhas do Departamento de Ecologia. Essa base de dados conta com dados no formato usual (DwC) e também com dados de interação entre estes.

A hospedagem deste provedor é de responsabilidade do LAA, e o processo de replicação foi realizado diretamente do servidor oficial, ou seja, no cenário exato, como ocorre na realidade do portal IABIN de polinizadores.

Este capítulo está dividido em etapas de testes e comparativos, conforme resumo a seguir:

- Configurações do provedor de dados singulares: Amostragem da quantidade de registros, campos mapeados e configurações do TAPIR dos dados singulares;

- Processo de replicação realizado no provedor de dados singulares: Descrição do processo que foi executado neste provedor para replicação de dados ao portal;

- Aplicação da fórmula no provedor de dados singulares: Aplicação das variáveis relacionadas a este provedor e seus resultados no uso da fórmula apresentada;

- Configurações do provedor de dados de interação: Amostragem da quantidade de registros, campos mapeados e configurações do TAPIR dos dados de interação; 
- Processo de replicação realizado no provedor de dados de interação: Descrição do processo que foi executado neste provedor para replicação de dados ao portal;

- Aplicação da fórmula no provedor de dados de interação: Aplicação das variáveis relacionadas a este provedor e seus resultados no uso da fórmula apresentada;

- Considerações finais: Apresentação confrontando os resultados reais e os mesmos obtidos através das fórmulas e o desfecho dos testes realizados nesse estudo de caso.

\subsection{Configurações do provedor de dados singulares}

O provedor de dados do CEPANN, no que se refere a dados singulares, segue a configuração padrão adotada pela maioria dos provedores de dados TAPIR. Um destaque é sobre o mapeamento desta base, que ocorre em todos os campos; dado o fato de sua ferramenta de aquisição de dados ter sida desenvolvida sobre o formato DwC por completo. Entretanto, muitos campos, não são preenchidos na base, mas pelo fato de poderem ser utilizados, devem obrigatoriamente permanecer mapeados.

Na Figura 15 pode-se ver uma parte da tela de mapeamento dos campos. 
unmap automap fill unmapped

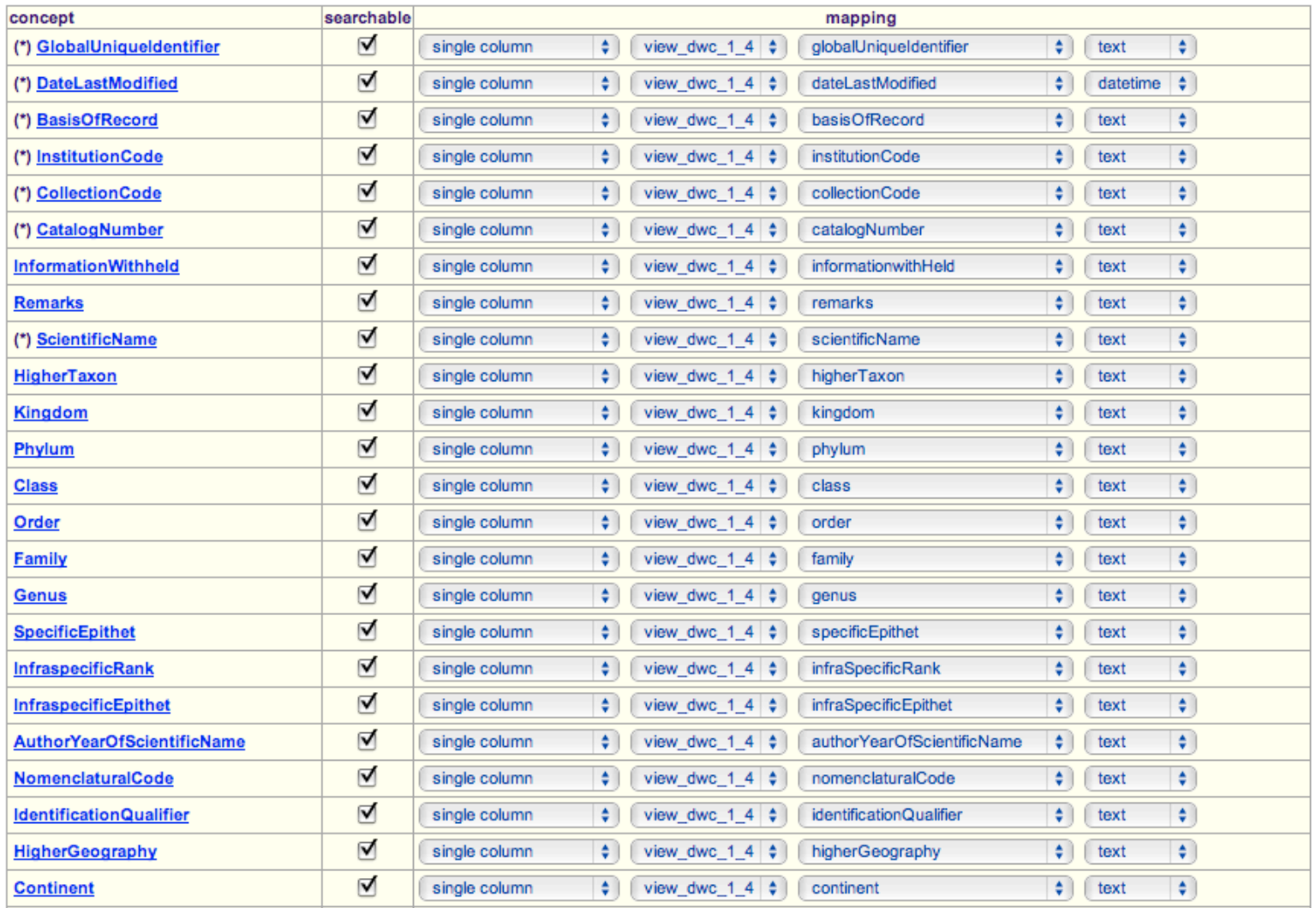

Figura 15 - Mapeamento dos campos do provedor no TAPIR

Ao todo são mapeados 61 campos, os quais incluem também dados georeferenciais. Apesar de ser abrangente, o mapeamento de muitos campos é responsável por uma carga muito grande na replicação, como veremos mais adiante. No que se refere à configuração de quantidade de registros por pacote, o valor estipulado já é o padrão adotado pelo TAPIR (de 200 registros por pacote). $\mathrm{Na}$ Figura 16 pode-se visualizar os dados gerais sobre os parâmetros de configuração deste provedor TAPIR. 


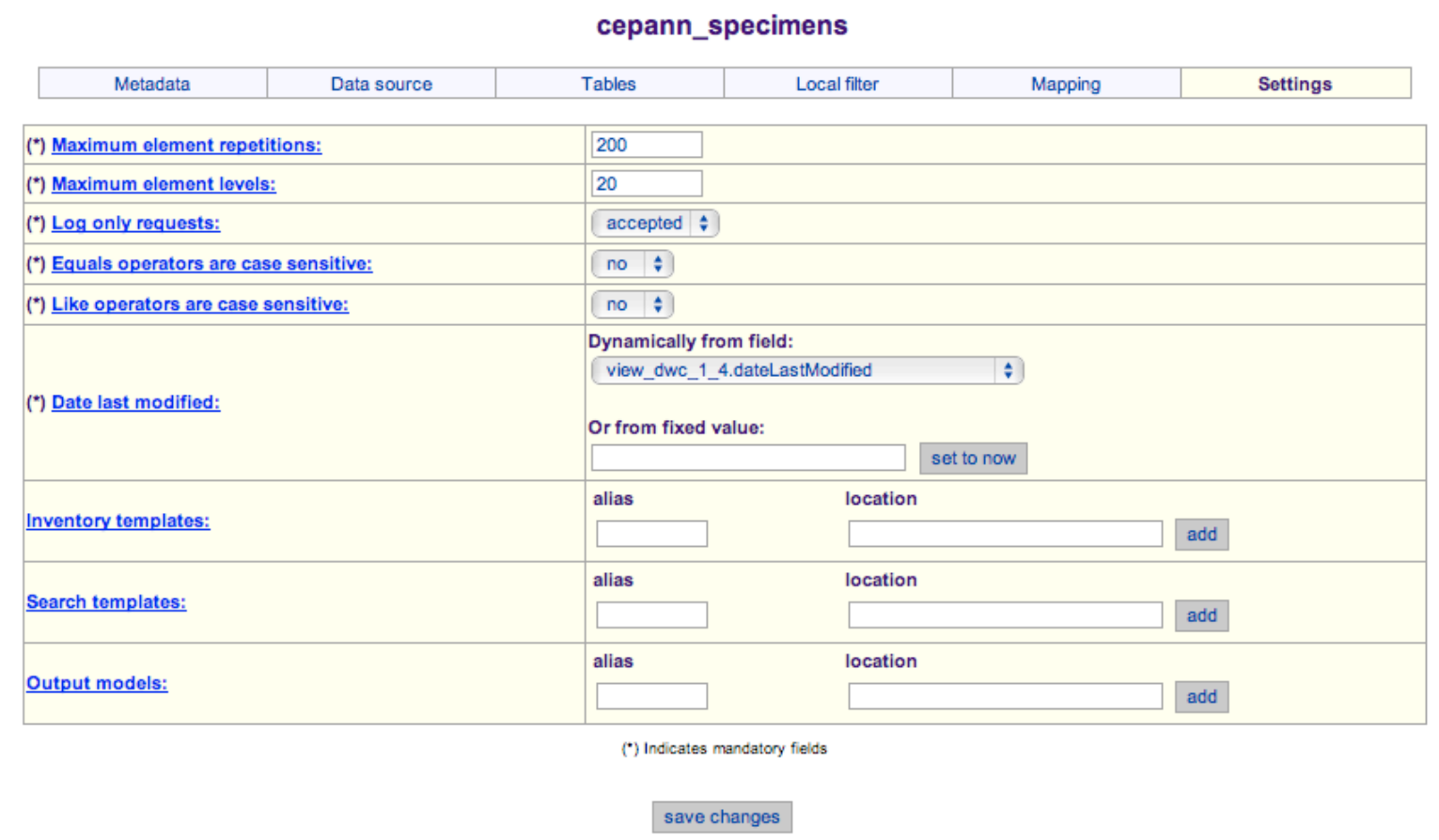

Figura 16 - Tela com as configurações do provedor TAPIR usadas para o provedor CEPANN

\subsection{Processo de replicação realizado no provedor de dados singulares}

Como citado anteriormente, o foco de atuação deste trabalho é em relação à etapa do processo da replicação dos registros do provedor para o portal, não tendo sido realizados testes envolvendo as demais etapas. Diferente dos testes realizados para a obtenção das fórmulas, este provedor TAPIR não foi modificado. A Tabela 5 apresenta o resumo dos dados e os resultados desta replicação.

Tabela 5 - Resultados reais obtidos no processo de replicação do CEPANN (DwC)

\begin{tabular}{|l|l|}
\hline DADOS GERAIS \\
\hline Quantidade total de registros & 35067 \\
\hline Quantidade de campos mapeados & 61 \\
\hline Velocidade de internet disponível no provedor & $10 \mathrm{Mb}+$ (Megabits por segundo) \\
\hline Velocidade de internet disponível no portal & $2 \mathrm{Mb}$ (Megabits por segundo) \\
\hline Quantidade de registros por pacote & 200 \\
\hline Servidor utilizado (fator de desempenho) & Xeon - 2GB RAM (6) \\
\hline RESULTADO & \\
\hline Tempo total do processo (em segundos) & 2159 \\
\hline
\end{tabular}




\subsection{Aplicação da fórmula no provedor de dados singulares}

Para obtenção de dados relativos ao desempenho da rede (velocidade e latência) foram realizados simples testes de transferências de arquivos (relativos aos tamanhos dos pacotes XML) entre as partes, no intuito de obter estas informações. Pode-se ver o quadro geral das variáveis através da Tabela 6 :

Tabela 6 - Dados variáveis para aplicação no modelo matemático

\begin{tabular}{|l|l|}
\hline \multicolumn{2}{|l|}{ DADOS VARIÁVEIS } \\
\hline totreg - Quantidade total de registros & 35067 \\
\hline ncampos - Quantidade de campos mapeados & 61 \\
\hline lat - Latência na comunicação & $32 \mathrm{~ms}(0,032 \mathrm{seg})$ \\
\hline banda - Velocidade média entre as partes & $725 \mathrm{kbps}=725000 \mathrm{bps}$ \\
\hline nreg - Quantidade de registros por pacote & 200 \\
\hline fd - Fator de desempenho no provedor & 6 \\
\hline
\end{tabular}

Seguem então as fórmulas e seus resultados:

$$
\begin{aligned}
& C P_{p a}=\text { nreg } * C R P=0,984 \\
& C P T_{p a}=\sum^{\text {nreg }} f d^{*} C R P T=3,6 \\
& T P_{p a}=\text { ncampos } * T R^{*} \text { nreg }=636840 \\
& V M R=\frac{\text { banda }}{8}=90625 \\
& C R_{p a}=\text { lat }+\frac{T P}{V M R}=7,0592 \\
& Q M P=\frac{\text { totreg }}{n r e g}=175,335 \\
& C F=\sum_{\text {QMP }}^{\text {QMr }}\left(C P_{p a}+C R_{p a}+C P T_{p a}\right)=2041,46
\end{aligned}
$$




\subsection{Configurações do provedor de dados de interação}

Os provedores de dados com suporte a interação foram desenvolvidos pela equipe de trabalho do LAA para o portal IABIN de polinizadores. Por se tratar de um conceito relativamente novo é válido também, verificar qual o impacto deste no que se refere a replicação de dados de interação, principalmente no caso do portal IABIN de polinizadores, cujo seu uso é de fundamental importância.

Por se tratar de um esquema diferente, é apresentado a aplicação de seus parâmetros na fórmula proposta, objetivando verificar se mesmo com as implementações, a mesma pode ser utilizada também para esta análise.

Diferente do padrão DwC, o esquema utilizado para dados de interação se restringe a somente 6 campos, sendo que somente um é opcional. Pode-se ver o mapeamento realizado no CEPANN (Interação) na Figura 17.

\begin{tabular}{|c|c|c|c|c|c|c|c|}
\hline & & unmap & automap & fill unmapped & & & \\
\hline concept & searchable & & & & apping & & \\
\hline (") InteractionGlobalUniqueldentifier & $\nabla$ & single column & * view & dwc_1_4_interaction & † InteractionGlobalUniqueldentifier & $\div$ text & $\uparrow$ \\
\hline (*) dateLastModified & $\nabla$ & single column & $\neq$ view_ & dwc_1_4_interaction & - dateLastModified & f datetime & $\uparrow$ \\
\hline (*) GlobalUniqueldentifier1 & $\checkmark$ & single column & $\uparrow$ view & dwc_1_4_interaction & $\neq$ globaluniqueidentifier1 & $\neq$ text & $\uparrow$ \\
\hline (*) Interaction & $\nabla$ & single column & $\neq$ view & dwc_1_4_interaction & interaction & $\rightarrow$ text & $\uparrow$ \\
\hline (") GlobalUniqueldentifier2 & $\nabla$ & single column & $\neq$ view & dwc_1_4_interaction & - globaluniqueidentifier2 & $\div$ text & $\uparrow$ \\
\hline RelatedInformation & $\nabla$ & single column & $\div$ view & dwc_1_4_interaction & interactionrelatedinformation & $\neq$ text & $\uparrow$ \\
\hline
\end{tabular}

Figura 17 - Mapeamento dos dados de interação do provedor TAPIR do CEPANN

Em relação às configurações de registros por pacote, como a quantidade de campos é consideravelmente menor neste tipo de esquema de dados (em relação ao DwC), mantendo-se 200 registros por pacote iria gerar pacotes muito pequenos, o que como será visto a seguir, impacta no desempenho. Para aproximar os tamanhos dos pacotes XML (nessa nova implementação) foram adotados 800 registros por pacote. A escolha desse valor não foi baseada nas análises feitas neste trabalho; mas, sim, através de alguns testes anteriormente realizados pela equipe de desenvolvimento.

Na Figura 18 pode-se, então, visualizar as configurações que foram adotadas para o provedor CEPANN de dados de interação. 


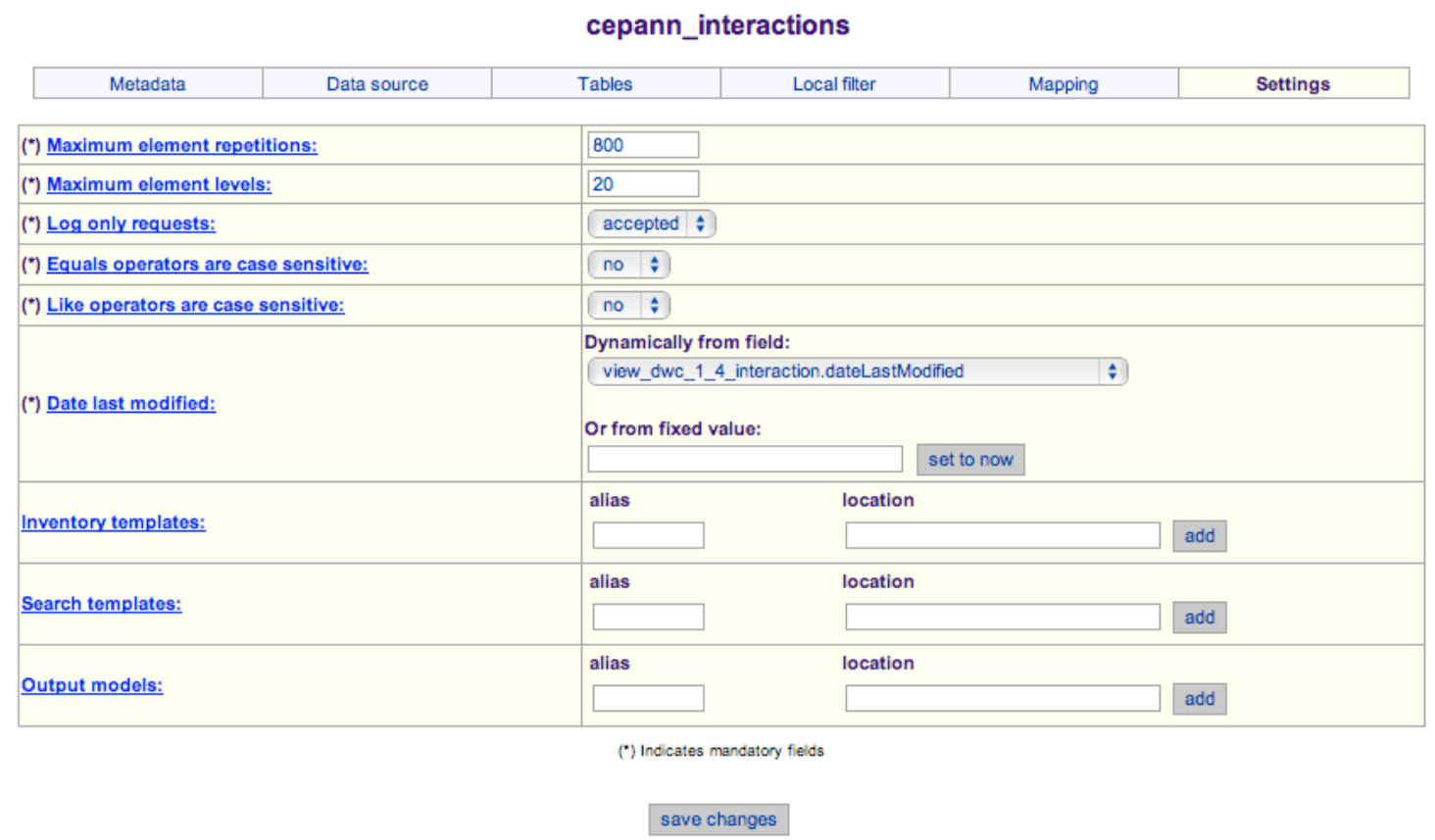

Figura 18 - Tela com as configurações do provedor TAPIR de interação do CEPANN

\subsection{Processo de replicação realizado no provedor de dados de interação}

Os provedores de interação têm como pré-requisito que os envolvidos em suas relações já tenham sido replicados anteriormente, no entanto, este processo, que não existe nos provedores de dados singulares (DwC), ocorre posteriormente a esta replicação. Essa é uma das principais diferenças sistemáticas entre as duas modalidades de provedor, que não faz parte das análises de resultados deste trabalho. Pode-se visualizar os dados referentes a este provedor através da Tabela 7.

Tabela 7 - Resultados reais obtidos no processo de replicação do CEPANN (interação)

\begin{tabular}{|l|l|}
\hline \multicolumn{2}{|l|}{ DADOS GERAIS } \\
\hline Quantidade total de registros & 17534 \\
\hline Quantidade de campos mapeados & 6 \\
\hline Velocidade de internet disponível no provedor & $10 \mathrm{Mb}+$ (Megabits por segundo) \\
\hline Velocidade de internet disponível no portal & $2 \mathrm{Mb}$ (Megabits por segundo) \\
\hline Quantidade de registros por pacote & 800 \\
\hline Servidor utilizado (fator de desempenho) & Xeon - 2GB RAM (6) \\
\hline RESULTADO & \\
\hline Tempo total do processo (em segundos) & 1161 \\
\hline
\end{tabular}




\subsection{Aplicação da fórmula no provedor de dados de interação}

Da mesma forma que fora anteriormente realizado no provedor de dados singulares, foram realizados testes da rede entre as partes para determinação de dados como latência e velocidade de banda. Pode-se visualizar todos os dados a serem utilizados nas fórmulas através da Tabela 8:

Tabela 8 - Dados variáveis para aplicação no modelo matemático

\begin{tabular}{|l|l|}
\hline \multicolumn{2}{|l|}{ DADOS VARIÁVEIS } \\
\hline totreg - Quantidade total de registros & 17534 \\
\hline ncampos - Quantidade de campos mapeados & 6 \\
\hline lat - Latência na comunicação & $31 \mathrm{~ms}(0,031 \mathrm{seg})$ \\
\hline banda - Velocidade média entre as partes & $807 \mathrm{kbps}=807000 \mathrm{bps}$ \\
\hline nreg - Quantidade de registros por pacote & 800 \\
\hline fd - Fator de desempenho no provedor & 6 \\
\hline
\end{tabular}

Seguem então as fórmulas e seus resultados:

$$
\begin{aligned}
& C P_{p a}=\text { nreg } * C R P=3,936 \\
& C P T_{p a}=\sum^{\text {nreg }} f d^{*} C R P T=14,4 \\
& T P_{p a}=\text { ncampos } * T R^{*} \text { nreg }=250560 \\
& V M R=\frac{\text { banda }}{8}=100875 \\
& C R_{p a}=\text { lat }+\frac{T P}{V M R}=2,5148 \\
& Q M P=\frac{\text { totreg }}{n r e g}=21,91 \\
& C F=\sum_{\text {QMP }}^{\text {QM }}\left(C P_{p a}+C R_{p a}+C P T_{p a}\right)=456,84
\end{aligned}
$$




\subsection{Considerações finais}

Após a realização dos testes reais e também da aplicação dos dados dentro da fórmula proposta foi possível elaborar uma tabela comparativa, abrangendo os resultados reais e projetados. A Tabela 9 apresenta o percentual de variação entre os dados reais e o projetado.

Tabela 9 - Comparativo dos resultados reais e propostos pelo modelo matemático

\begin{tabular}{|l|c|c|c|}
\hline \multicolumn{1}{|c|}{ Base de dados } & $\begin{array}{c}\text { Tempo real do } \\
\text { processo } \\
\text { (em segundos) }\end{array}$ & $\begin{array}{c}\text { Tempo da } \\
\text { formula } \\
\text { (em segundos) }\end{array}$ & Variação \\
\hline CEPANN - Dados singulares & 2159 & 2041 & $5,47 \%$ \\
\hline CEPANN - Dados de interação & 1161 & 456 & $60,72 \%$ \\
\hline
\end{tabular}

Pode-se ver claramente através desta tabela que a fórmula apresentou uma variação pequena nos dados singulares e uma variação muito grande nos dados de interação. No capítulo a seguir, é apresentado um diagnóstico mais detalhado sobre estes resultados, bem como o motivo de a fórmula apresentada não ter sido adequada para o caso dos dados de interação. 


\section{DISCUSSÃO DOS RESULTADOS}

Neste capítulo são discutidos os resultados obtidos durante a elaboração da fórmula proposta neste trabalho, bem como sua aplicação no estudo de caso em comparação com os valores efetivos obtidos durante este processo de replicação. Este capítulo esta dividido em três partes:

- Discussão sobre os resultados obtidos para elaboração da fórmula: Destaca os pontos identificados durante a extração dos pontos de notificação e seus comportamentos durante o processo;

- Discussão sobre os custos entre provedor, portal e rede: Em uma abordagem mais dinâmica, é realizada uma planilha de simulações utilizando a fórmula deste trabalho para determinar e discutir sobre os custos individuais do provedor, portal e rede dentro do processo de replicação;

- Discussão sobre os resultados do estudo de caso: Apresenta os pontos relevantes durante os testes reais executados no estudo de caso e sua aplicação dentro dos parâmetros do modelo proposto neste trabalho.

\subsection{Discussão sobre os resultados obtidos com a utilização da fórmula}

A elaboração da fórmula teve como referência os testes que foram realizados em provedores criados especificamente para esta finalidade e, durante a extração dos resultados dos testes, foram realizadas várias execuções, de forma a se obter uma média dos resultados. Durante a extração dos resultados notou-se uma série de fatores interessantes relacionados ao desempenho do processo.

A primeira impressão notada foi que ao utilizar 50 registros por pacote foi obtido um desempenho na rede inferior ao utilizar 200 ou 400 registros por pacote. Este fato ocorreu em condições de rede similares, pois foram realizados em um período com pouco tráfego, um seguido do outro. Para buscar a justificativa do ocorrido, foram realizados testes com transferência de arquivos em lote entre as partes. Constatou-se que para arquivos pequenos (equivalente aos pacotes menores de 50 registros cada), não se atinge a velocidade esperada (que ocorre em pacotes maiores), isto independente de se transferir entre provedor e portal, como 
pelo próprio navegador de internet. Sendo assim, pode-se supor que esta perda de desempenho esteja vinculada a características da arquitetura de redes.

Como conclusão desta análise foi observado que, mesmo em condições de banda iguais, os pacotes maiores (de 200 ou 400 registros) obtêm um ganho comparado aos pacotes menores, relacionado à transferência pela rede.

Após as extrações dos pontos de notificação, foi verificado outro fato interessante. Ao efetuar o uso de maiores quantidades de registros por pacote (por exemplo, mais de 400) em alguns casos, o processo obtinha ganho de desempenho e em outros não. Ainda, analisando em maiores detalhes, foi verificado que isto estava diretamente vinculado ao desempenho do servidor utilizado no provedor.

$\mathrm{O}$ aumento dos registros por pacote ocasionava melhoria até certo ponto, a partir deste ponto, o desempenho começava a ficar inferior. Foi constatado que este ponto ideal varia de acordo com o servidor utilizado no provedor de dados. Para permitir que a fórmula fosse mais adequada, foi limitada a faixa de registros por pacote entre 50 e 400 no modelo matemático, valores que demonstraram um padrão durante todos os testes.

Após a realização de todos os testes, foi feita uma comparação entre os valores reais de desempenho e os valores simulados pela fórmula. Estes testes tiveram como objetivo verificar o nível de confiabilidade dos resultados obtidos pelas fórmulas. Ao longo das comparações, tivemos uma variação de, no máximo, 6,04\% do valor real. Dada a quantidade de variáveis e a complexidade envolvidas no processo, esta variação foi considerada aceitável para os objetivos deste trabalho.

\subsection{Discussão sobre os custos entre provedor, portal e rede}

Como visto anteriormente, existem 3 elementos distintos envolvidos no processo de replicação de dados: Provedor, Portal e a Rede. Desde o início dos testes foram tomadas medidas para que fosse possível determinar o custo individual de cada um destes elementos no processo.

Para gerar uma situação comparativa, usamos a fórmula para obter os custos individuais e determinar o seu percentual em relação aos demais no processo. Pode-se ver, através da Tabela 10, alguns cenários fictícios utilizados para demonstrar tal comparação. 
Tabela 10 - Cenários para testes de comparação de custos

\begin{tabular}{|c|c|c|c|c|c|c|}
\hline Cenário & $\begin{array}{l}\text { Quant. } \\
\text { total de } \\
\text { registros }\end{array}$ & $\begin{array}{c}\text { Quant. de } \\
\text { registros } \\
\text { por } \\
\text { pacote }\end{array}$ & $\begin{array}{l}\text { Quant. de } \\
\text { campos } \\
\text { mapeados }\end{array}$ & $\begin{array}{l}\text { Desemp. } \\
\text { do } \\
\text { provedor }\end{array}$ & $\begin{array}{l}\text { Latência } \\
\text { média } \\
\text { (em } \\
\text { segundos) }\end{array}$ & $\begin{array}{c}\text { Banda } \\
\text { média (em } \\
\text { kilobits por } \\
\text { segundo) }\end{array}$ \\
\hline T1 & \multirow{7}{*}{100.000} & 50 & \multirow{7}{*}{61} & 5 & \multirow{7}{*}{0,030} & 1000 \\
\hline T2 & & 200 & & 5 & & 1000 \\
\hline T3 & & 400 & & 5 & & 1000 \\
\hline T4 & & 200 & & 7 & & 1000 \\
\hline T5 & & 200 & & 3 & & 1000 \\
\hline T6 & & 200 & & 5 & & 500 \\
\hline T7 & & 200 & & 5 & & 2000 \\
\hline
\end{tabular}

Com base nos cenários apresentados, foram enquadrados os valores nas fórmulas, obtendo-se de forma separada o custo do provedor, do portal e da rede. Estes também foram enquadrados em percentual. Através da Figura 19 pode-se visualizar melhor os resultados obtidos.

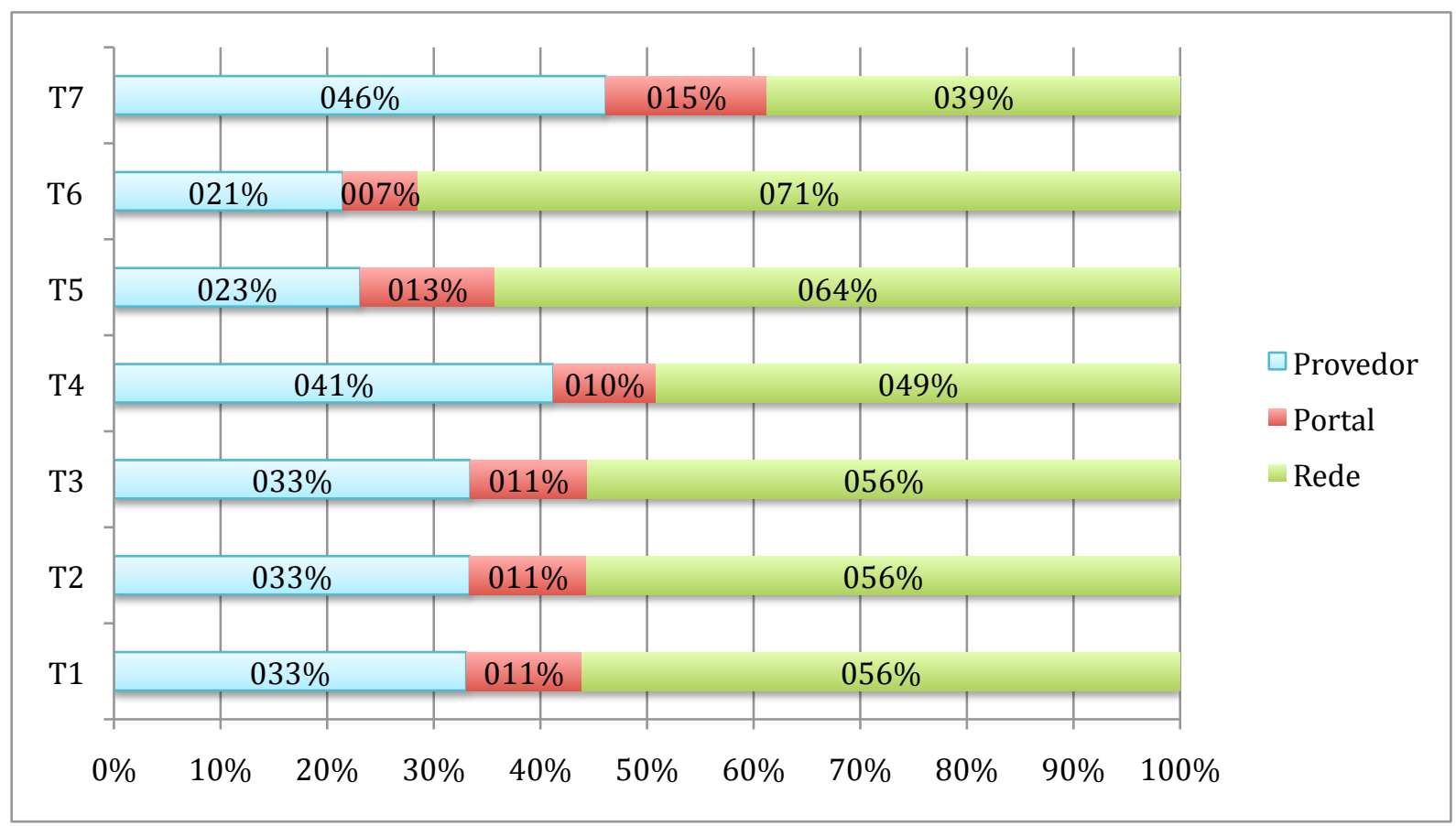

Figura 19 - Gráfico com os resultados dos custos de cada processo obtidos nos cenários para testes

Pode-se notar que a variação de números de registros por pacote não altera significativamente o custo entre os três envolvidos. Sendo assim, resta uma análise 
mais comparativa sobre as outras variações que foram utilizadas nos valores: desempenho do servidor, do provedor e da banda.

No caso da alteração de desempenho nota-se que a melhoria do desempenho do servidor entre as três opções testadas (3, 5 e 7) gera uma oscilação na média de quase $10 \%$ do custo do provedor. Mas, apesar disso, o grande percentual do tempo gasto no processo fica relativamente vinculado à banda disponível.

No caso da banda disponível, o aumento da velocidade ocasionou em uma diminuição significativa do custo da rede no processo; porém, deve-se deixar claro que as condições de rede tendem a variar durante todo o processo e no uso de quantidade de registros por pacote pequenas, pode-se obter um desempenho insatisfatório, conforme anteriormente aduzido.

Já em uma análise centrada, mais focada no portal, notamos que o mesmo detém somente um pequeno percentual do processo e isto significa que melhorias realizadas neste podem não gerar uma melhoria significativa no processo como um todo.

\subsection{Discussão sobre os resultados do estudo de caso}

O uso do estudo de caso neste trabalho teve como objetivo demonstrar a aplicação da fórmula para comparação com uma situação real de replicação de dados de um provedor de dados, bem como verificar comparativamente o impacto nos mesmos moldes da recente implementação da replicação dos dados de interação.

O provedor escolhido foi o CEPANN, por se localizar na própria USP e ser de cuidados técnicos do LAA, o que possibilitou acesso a informações técnicas da disponibilização deste, bem como a quantidade exata de registros, a quantidade de campos mapeados e informações sobre o servidor utilizado.

O processo de replicação foi realizado nos mesmos moldes utilizados na situação real, e tudo ocorreu como previsto durante a replicação dos dados entre o portal e o provedor. Tanto antes do início dos testes, como no final, foram obtidas diversas amostras para detectar as condições às quais o teste estava sendo realizado. Após os preenchimentos dos dados e o uso da fórmula para simular os custos do processo, chegou-se a um resultado com uma variação de $5,47 \%$, dentro 
da faixa limite obtida nos testes iniciais para elaboração da fórmula. Sendo assim, considerou-se aceitável o comportamento da fórmula também nesta situação real.

Com intuito de avaliar também o processo de replicação de dados de interação, foi executada a tentativa do uso das mesmas fórmulas pelas seguintes razões:

- O protocolo TAPIR permanece e faz uso das mesmas características, exceto o esquema de dados que é diferenciado;

- Apesar de diferenciado, o esquema de dados segue um padrão similar ao DwC sendo diferenciado pela quantidade de campos e pelas suas nomenclaturas;

- O portal usa as mesmas rotinas padrões nesta etapa do processo somente tendo como diferencial a exemplificação deste esquema de dados novo em seu código (para maiores detalhes ver Apêndice A).

Inicialmente, era esperado que a fórmula pudesse avaliar este processo com um índice de variação maior, porém ainda aceitável, mas não foi o que ocorreu. A variação foi de $60,72 \%$, o que se mostrou inviável para ser um método adequado de simulação. Após a realização dos testes e de várias execuções do processo, foram avaliados os elementos em busca de tal diferença e foi possível obter alguns pontos:

- A quantidade baixa de campos mapeados e seus conteúdos diferenciados distorcem os valores propostos na fórmula com uso do modelo $\mathrm{DwC}$, no que se refere ao tamanho final do pacote;

- O provedor TAPIR possui um custo para formulação dos registros, como no DwC a quantidade de campos é até aproximadamente 10 vezes maior, este custo foi englobado na média dentro do custo por registro. Este percentual é muito mais significativo em um esquema com somente 6 campos; o custo, neste caso, deveria ser reavaliado e considerado na nova fórmula;

- O modelo de saída utilizado neste novo esquema de dados não é nativo do TAPIR e isto torna necessária sua consulta externa (este ponto pode ser amenizado implantando uma copia deste modelo localmente);

- O código do portal não seguiu as proporções de eficiência esperadas com um esquema utilizando uma quantidade tão inferior de campos. 


\section{CONCLUSÃO}

A necessidade de integrar dados de diferentes provedores dentro de um único portal centralizador já é um desafio que envolve diversos elementos. Quando consideramos as diferentes comunidades computacionais envolvidas paralelamente em prol desta área de biodiversidade, é uma grande conquista estas conseguirem apresentar e seguir padrões.

Fazendo parte ao longo de quase três anos da equipe envolvida com o projeto IABIN na Poli-USP, foi possível conviver com o uso destes padrões e entender melhor as técnicas computacionais adotadas para esta pesquisa. Dentre as etapas presenciadas, a de replicação dos dados entre o provedor e o portal foi que despertou maior interesse para uma análise mais detalhada. Tanto por se tratar de um processo demorado como também pela sua importância dentro do portal.

O foco se concentrou em dividir os custos envolvidos entre as três partes deste processo: portal, provedor e rede. Para isso, o uso dos pontos de notificação demonstraram sua eficácia, uma vez que, os resultados obtidos demonstraram a eficiência esperada para a finalidade central deste trabalho.

Inicialmente, enfocando na discussão dos resultados como um todo, foi contemplado que a participação da rede de dados dentro do processo de replicação é bastante significativa. Os dados trafegados usam o padrão XML, que é um formato texto devidamente parametrizado. Em uma análise mais detalhada de um pacote de dados foi possível constatar que este, em muitos casos, possui mais informações de parametrização do que o conteúdo dos registros em si.

Este fato torna os pacotes pouco otimizados, considerando-se que trazem informações repetitivas de parametrização, as quais geram custo no seu tráfego pela rede. Este trabalho não teve como objetivo avaliar alternativas viáveis e seus impactos, mas claramente uma mudança na forma de parametrização ou até mesmo a adoção de algum tipo de compactação impactaria diretamente nesta etapa e em todo o processo consequentemente.

Para exemplificar, executamos a compactação $T A R / G Z$ de um pacote de dados de amostra para comparação no tamanho do mesmo. Pode-se ver o resultado através da Tabela 11. 
Tabela 11 - Comparação na compactação de um pacote de dados trafegado pelo provedor

\begin{tabular}{|l|l|l|}
\hline Tamanho original (em bytes) & $\begin{array}{l}\text { Tamanho compactado } \\
\text { (em bytes) }\end{array}$ & $\begin{array}{l}\text { Tamanho em } \\
\text { relação ao original }\end{array}$ \\
\hline 818.754 & 14.908 & $1,82 \%$ \\
\hline
\end{tabular}

O tamanho se mostra bem inferior ao original, principalmente pelo fato de os compactadores serem altamente eficientes, com arquivos que contêm somente texto. Resumidamente, poderiam ser colocados mais de 54 pacotes com o tamanho de um apenas. O que comprova que um trabalho futuro neste ponto critico geraria grandes contribuições para o protocolo e esquema de dados.

Ainda referente ao pacote de dados, foi verificado que quando mapeamos um determinado campo do esquema de dados, este irá constar parametrizado em todo registro, independente de o mesmo conter ou não um valor. Este fato pode gerar, em muitos casos, em registros com poucas informações, uma maior quantidade de campos parametrizados sem conteúdo, aumentando o tamanho do pacote de dados de forma desnecessária.

Avaliando agora, em nível do conjunto de pacotes de dados, é pertinente explanar sobre a indexação de dados que ocorre na segunda etapa do processo de Harvest. A todo provedor é solicitado uma indexação por nome científico, em que são geradas faixas de nomes científicos com uma quantidade balanceada de dados em cada uma delas. O objetivo desta indexação é dividir as solicitações em menores partes junto aos provedores, beneficiando-se assim, na obtenção somente de dados adicionais ou alterados após a primeira replicação. A técnica específica de atualização dos dados replicados não foi abordada neste trabalho, mas é pertinente, por se constatar que a mesma não é necessária na replicação dos dados pela primeira vez.

A explicação para a não necessidade do uso destes indexadores na primeira obtenção dos dados é dada pelo fato de que não há benefícios em dividir as solicitações, haja vista que todas serão usadas. Além do mais, a divisão gera um custo adicional, pois, quanto maior a quantidade de ciclos, maiores as chances de pacotes não totalmente "cheios". Por exemplo, se foi optado por usar 200 registros por pacote e um ciclo contém 201 registros, haverá um retorno com 200 registros e outro com somente 1 registro. Mas isso poderá ocorrer diversas vezes, dependendo 
do número de ciclos necessários pela indexação realizada para aquele determinado provedor.

Como se pode notar, existem diversos pontos que podem ser reavaliados no que se refere à etapa a qual envolve a transmissão dos dados entre o portal e o provedor de dados. E algumas dessas alterações, poderiam, inclusive, ser efetuadas sem mudanças significativas na arquitetura atualmente utilizada.

Adicionalmente, temos outras iniciativas fazendo a reutilização destas técnicas que conseqüentemente herdam não só os seus benefícios mas também, seus pontos críticos. Um exemplo é a implementação mais recente de suporte a dados de interação (ver Apêndice A para maiores detalhes) que usou a mesma arquitetura já existente de dados DwC. Com o uso desta mesma fórmula proposta neste trabalho avaliou-se também este processo adaptado para interação, e como pode-se visualizar nos resultados e na discussão dos mesmos, o processo se mostrou ineficiente seguindo esta projeção. Fica claro que as fórmulas não são adequadas para esta representatividade dado a fatores já citados no capítulo anterior; no entanto, a relação de registros trafegados pelo tempo e condições é muito inferior ao equivalente em um processo de replicação convencional.

Concluindo, temos duas diferentes linguagens sendo utilizadas, uma em cada elemento envolvido (provedor e portal) e, por terem sido desenvolvidas por equipes diferentes, ambas possuem pontos a serem reavaliados no sentido de maximizar o desempenho do processo. No entanto, uma medida sobre o formato pelo qual os dados são trafegados poderia gerar um impacto ainda maior, como foi confirmado nos resultados obtidos à amplitude de sua participação no processo de replicação. Mas, como principal contribuição, este trabalho fornece dados e ferramentas capazes de auxiliar nas análises de desempenho de processos de replicação entre portais e provedores com uso de protocolo TAPIR e esquema de dados DwC. Além de simular situações auxiliando na tomada de decisões sobre a publicação de novos provedores de dados. É esperado que novos trabalhos sejam desenvolvidos nesta linha de pesquisa e façam uso destas ferramentas em benefício da informática para biodiversidade. 


\section{REFERÊNCIAS}

BATINI C.; LENZERINI M.; NAVATHE S. B. A comparative analysis of methodologies for database schema integration. ACM Comput. Surv, v. 18, p. 323364. New York, NY, USA, 1986.

BIOCASE. Biological Collection Access Services. Disponível em: <http://www.biocase.org/> . Acesso em: 02 out. 2009.

BOEYEN C. A. S. UDDI and WSDL extensions for Web service: a security framework. In: XMLSEC '02: PROCEEDINGS OF THE 2002 ACM WORKSHOP ON XML SECURITY. p.30-35. New York, USA, 2002.

CANHOS, V.P.; SOUZA, S.; GIOVANNI, R.; CANHOS, D. A. L. Global biodiversity informatics: setting the scene for a "New World" of ecological modeling. Biodiversity Informatics, v. 1, p. 1-13, 2004.

CÔRREA, P. L. P. Diretrizes e procedimentos para o projeto de bases de dados. 2002. Tese de doutorado. Departamento de Engenharia de Computação e Sistemas Digitais da Escola Politécnica da Universidade de São Paulo. São Paulo, 2002.

DIGIR. Distributed Generic Information Retrieval. Disponível em: <http://www.digir.net/>. Acesso em: 05 mar. 2009.

DWC. DarwinCore Schema. Disponível em: <http://www.tdwg.org/activities/darwincore/>. Acesso em: 15 mar. 2009.

GBIF. Global Biodiversity Information Facility. Disponível em: <http://www.gbif.org/>. Acesso em: 05 mar. 2009.

GRAHAM, C.H.; FERRIER, S.; HUETTMAN, F.; MORITZ, C.; PETERSON, A. T. New developments in museum-based informatics and applications in biodiversity analysis. Trends in Ecology \& Evolution, v. 19, n. 9, p. 497-503, Set. 2004.

HEMRAJANI A. Desenvolvimento ágil em JAVA com Spring, Hibernate e Eclipse. São Paulo: Pearson Prentice Hall, 2006. 290p. 
HOUSE N. A. V. Trust and epistemic communities in biodiversity data sharing. In: JCDL '02: PROCEEDINGS OF THE 2ND ACM/IEEE-CS JOINT CONFERENCE ON DIGITAL LIBRARIES p. 231-239. New York, NY, USA, 2002.

IABIN. Inter-American Biodiversity Information Network. Disponível em: <http://www.iabin.net/>. Acesso em: 07 fev. 2009.

IABIN-PTN. IABIN - Rede Temática de Polinizadores. Disponível em: <http://pequi.pcs.usp.br/portal/>. Acesso em: 07 out. 2009.

INTERACTION EXTENSION: Interaction Extension Schema. Disponível em: $<$ http://wiki.tdwg.org/twiki/bin/view/DarwinCore/InteractionExtension/>. Acesso em: 05 fev. 2009.

JOHNSON R. Introduction to the Spring Framework. 2005. Artigo disponível em: $<$ http://www.theserverside.com/tt/articles/article.tss?l=SpringFramework>. Acesso em: 27 jul. 2009.

OZSU T. M.; VALDURIEZ P. Principles of Distributed Database Systems. 2. [S.I]: Prentice Hall, 1999.

SALVANHA, P., NAJM L. H., CORRÊA P. L. P.; SARAIVA A. M. Model of management and sharing distributed interaction pollinators information for centralized biodiversity portals. In: 5th CONTECSI INTERNATIONAL CONFERENCE ON INFORMATION SYSTEMS AND TECHNOLOGY MANAGEMENT. São Paulo, Brazil, 2009.

SARAIVA, A.M. Tecnologia da informação na agricultura de precisão e biodiversidade: estudos e proposta de utilização de Web Services para desenvolvimento e integração de sistemas. 2003. 209p. Tese (Livre Docência) Departamento de Engenharia de Computação e Sistemas Digitais, Escola Politécnica, Universidade de São Paulo, São Paulo, 2003.

STEVENSON, R. D.; MORRIS, R. A. Community science for biodiversity monitoring. In: 2002 ANNUAL NATIONAL CONFERENCE ON DIGITAL GOVERNMENT RESEARCH. Los Angeles, California, 2002.

TAPIR. Distributed Generic Information Retrieval. Disponível em: <http://wiki.tdwg.org/TAPIR / >. Acesso em: 02 fev. 2009. 
UDDI. UDDI Spec Technical Committee Draft. Disponível em: <http://uddi.org/pubs/uddi_v3.htm>. Acesso em: 10 fev. 2009.

XU, X., JONES, A. C., GRAY, W. A., FIDDIAN, N. J., WHITE, R. J.; BISBY, F. A. Design and performance evaluation of a web-based multi-tier federated system for a catalogue of life. In: 4th INTERNATIONAL WORKSHOP ON WEB INFORMATION AND DATA MANAGEMENT. McLean, Virginia, USA, 2002. 


\section{APÊNDICE A}

\section{Implementação do suporte a dados de interação}

Até o momento já foi desenvolvido de forma consolidada o processo de suporte a dados de interação no portal de biodiversidade baseada no portal GBIF. Os tópicos a seguir descrevem as etapas e seus impactos de alterações no projeto original.

\subsection{Esquema de dados de interação}

O esquema de dados de interação desempenha um papel fundamental em todo o processo, pois é através dele, que os dados necessários são transmitidos do provedor para o portal. Os atuais protocolos utilizados, oferecem suporte ao uso de diferentes esquemas de dados nativamente, no entanto, o processo do portal é diferente, pois exige um suporte diferenciado, para obtenção desses dados em sua base.

Apesar dos dados de interação estarem ligados diretamente aos dados singulares (DwC), os mesmos não se enquadram como simples dados complementares. O vinculo estabelecido é entre dois registros singulares (DwC). A modelagem necessária para estruturar este vinculo é realizada no banco de dados do portal em duas novas tabelas:

- Modelo de dados RAW: Contém os campos exatamente como existem no esquema de dados. Este modelo é utilizado para a replicação de dados da forma original entre o provedor e o portal.

- Modelo de dados operacional: Trata-se do modelo usado pelo DAO / DTO para o portal como um todo, seja nas buscas de dados, como também, na obtenção das informações de um registro específico. Este modelo é criado baseado no modelo de dados RAW.

Os paradigmas envolvidos são baseados na representação deste relacionamento, os dados singulares podem em diversas ocasiões interagir com um ou mais elementos, justificando o uso de "muito para muitos" no modelo utilizado 
pelo portal. Na Figura 20 podemos visualizar a modelagem para o banco de dados local do portal utilizada.

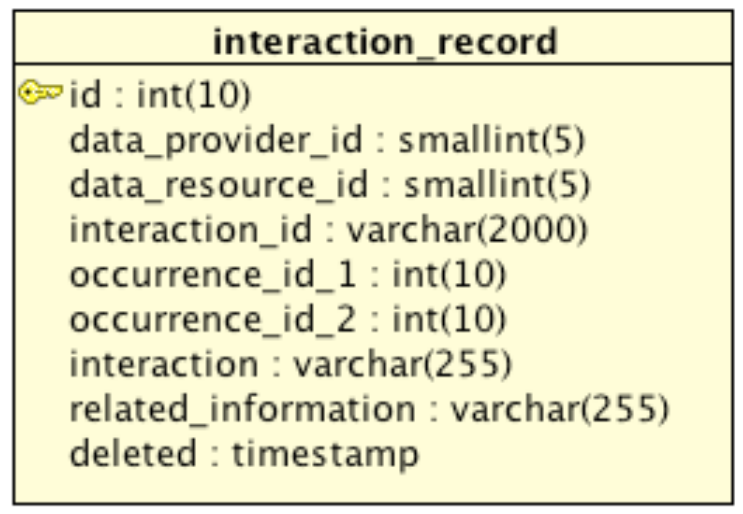

Figura 20 - Modelagem do banco de dados local do portal

Com base nesta nova modelagem, foi desenvolvido um novo esquema de dados específico para dados de interação, que faz utilização dos campos de chave primária remotos (denominados Global Unique Identifier) dos registros envolvidos em um registro único e exclusivo para esta finalidade.

\subsection{Adequação do código fonte baseado no portal GBIF}

O portal de referência utilizado é o do projeto GBIF, que já abrange o uso dos protocolos e modelos atuais voltados a biodiversidade. O portal do GBIF no entanto não engloba nenhum tipo de suporte a dados de interação, que foi implementada através deste novo projeto.

Este projeto foi desenvolvido em linguagem Java usando frameworks como: Spring, Hibernate e Velocity. Sua divisão foi em módulos, proporcionando uma melhor divisão de funcionalidades, no entanto, a falta de documentação dificultou a padronização da nova implementação e o entendimento dos recursos já existentes. Mas todas foram realizadas seguindo os padrões definidos no código.

Os módulos que necessitaram de alterações foram:

- Portal-core: Núcleo principal do projeto, contendo as bibliotecas de apoio;

- Portal-index: Classes de execução para rotinas de replicação de dados, inserção em lote, entre outras. 


\subsubsection{Portal-Core}

Como este módulo disponibiliza ferramentas para os demais não houve necessidade de alteração de código fonte, no entanto, o mesmo contem o modelo de base de dados, no qual foram necessárias as inclusões de duas tabelas (raw_interaction_record e interaction_record). Uma baseada no esquema de dados de interação e outra no banco de dados relacional do portal (conforme citado anteriormente). Adicionalmente foi necessário incluir dois novos namespaces (que fazem a relação com o mapa de campos) para suportar o novo esquema de dados de interação.

\subsubsection{Portal-Index}

Este módulo contém todo o processo referente ao Harvest (replicação e indexação de dados). Tal processo engloba tanto as informações que homologam o esquema de dados, como as que reconhecem o mesmo tornando-o acessível para o portal. Esse reconhecimento abrange também o processo de transferência e validação das informações envolvidas. As alterações foram necessárias em diversas instancias conforme tópicos a seguir.

7.2.2.1. Pacotes / classes implementadas para interação

- org.iabin.portal.dao

- Registro RAW de interação e o registro relacional.

- org.iabin.portal.dao.impl.jdbc

- Implementação dos DAOs de interação

- org.iabin.portal.harvest.wizard

- Extração dos registros RAW

- org.iabin.portal.harvest.workflow.activity

- Processo de requisição com o provedor

- org.iabin.portal.harvest.workflow.activity.wizard

- Interface com o provedor 
- org.iabin.portal.model

- Modelo do RAW e do registro relacional.

\subsubsection{Resources - Spring Beans}

Implementação dos namespaces e seus processos (baseados no DwC original e protocolo TAPIR):

- org.iabin.portal.util.propertystore.dwe_1_0

- org.iabin.portal.util.propertystore.iabin_indexing_1_0

- org.iabin.portal.util.propertystore.tapir_1_0_dwe_1_0

Suporte ao TAPIR usando DWE (esquema de interação), além das etapas do processo de requisição e extração.

7.2.2.3. Gerenciamento dos contextos de suporte ao processo

Para o gerenciamento dos contextos existentes no Spring, foi necessária a criação dos beans, que são referenciados em todo o processo nos namespaces. É de fundamental importância esta inclusão, assim como seu devido ajuste ao suporte da interação, pois, o mesmo oferece o intermediário de alocação e tratamento dos dados antes do seu desfecho na base de dados local do portal.

7.2.2.4. Inclusão dos novos namespaces no portal

- org.gbif.portal.util.propertystore : Foi necessária a inclusão dos dois novos namespaces no contexto para o suporte e reconhecimento dos mesmos pelas demais implementações do portal. Segue na Figura 21 a inclusão: 
<!-- INICIO DE ALTERAÇÃO IABIN PTN INTERACTION -->

$<$ entry key="http://groselha.pcs.usp.br/schemas" value-

ref="propertyStore:namespace:DWE:1.0"/>

<entry key="http://rs.tdwg.org/dwe/tapir/1.0" value-

ref="propertyStore:namespace:TAPIR:DWE:1.0"/>

$<!--$ FIM DE ALTERAÇÃO IABIN PTN INTERACTION -->

Figura 21 - Trecho incluído diretamente no código do portal GBIF

Para que o protocolo TAPIR possa operar de acordo esse novo esquema de dados, é necessária a compatibilidade e citação deste no protocolo, e somente o novo namespace não preenche este requisito. Foi necessário também reformular a forma de indexação utilizada, assim como a alteração no modelo de saída. Por padrão (no esquema DwC) é utilizada a indexação por nome científico, campo que não existe no esquema de interação, assim foi adotado o campo "Interaction" para esta finalidade.

\subsubsection{Considerações sobre a indexação}

A indexação foi realizada na mesma tabela usada pelo esquema de dados padrão (DwC), a justificativa é minimizar o impacto da nova implementação, assim como, armazenar os datasets de forma centralizada. A ausência de certos vínculos neste novo esquema (em relação ao DwC), como a taxonomia, diminuem significativamente a necessidade de rotinas SQL (Structured Query Language) necessárias no término do processo. Adicionalmente, a contagem de registros de interação não interferem no número de ocorrências existentes do portal, visto que, trata-se somente da interação entre elas.

\subsubsection{Modelo de saída (output model)}

Para o protocolo TAPIR operar é necessário que o mesmo adote um modelo de saída dos dados, e tal modelo deve, ser coerente com a proposta do esquema de dados utilizado, assim como, com o formato de recebimento do mesmo pelo portal. 


\section{Por se tratar de um esquema de dados diferenciado em relação ao padrão (DwC), foi desenvolvido um novo output model exclusivo para esta finalidade, como pode-se ver na Figura 22 o modelo pronto.}

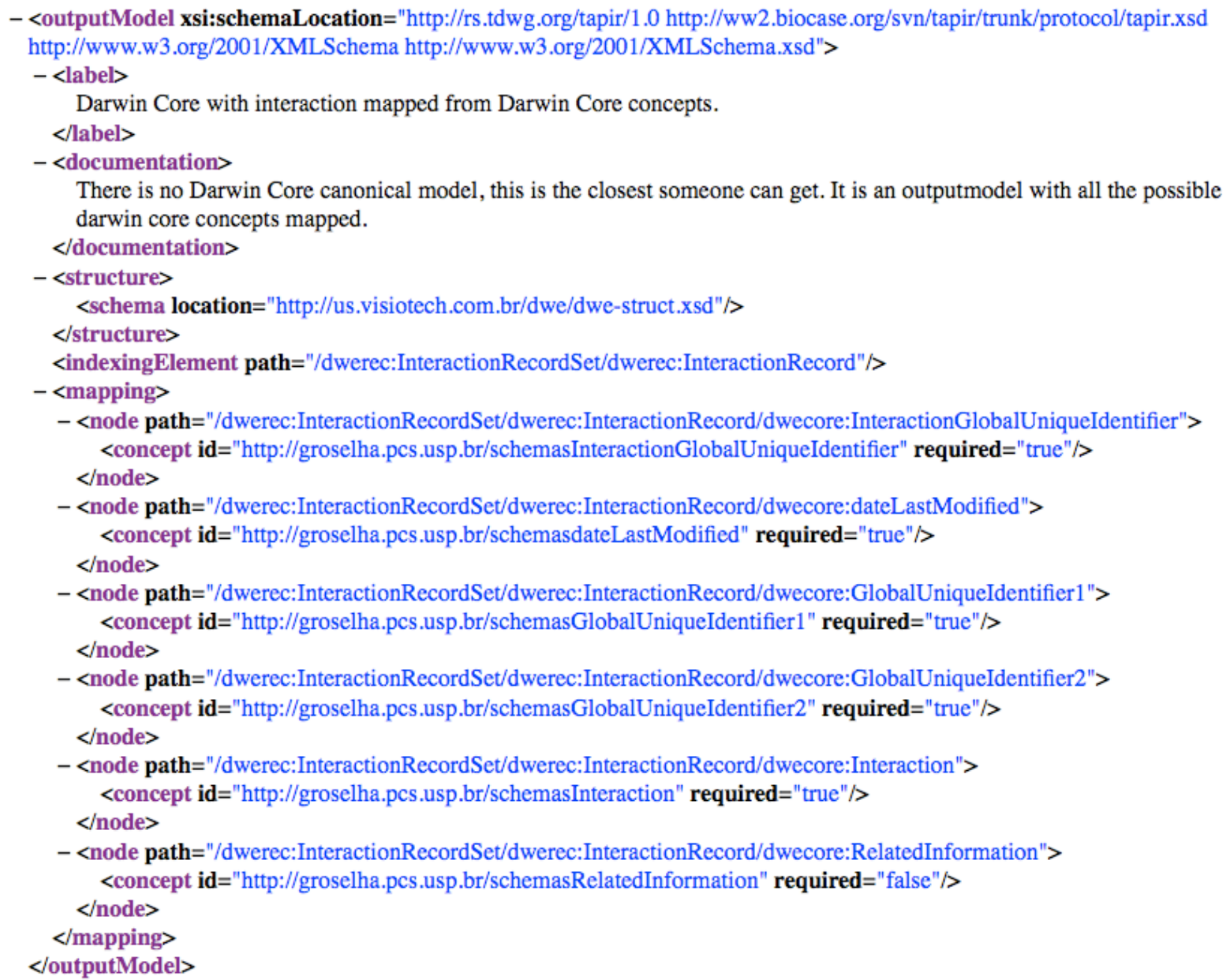

Figura 22 - Modelo de saída (output model) adotado para metadados de interação 


\section{APÊNDICE B}

\section{Etapas envolvidas no processo de Harvest}

Os portais de biodiversidade como do GBIF, necessitam de provedores para povoar suas bases de dados. Este processo, onde os portais recebem informações de um determinado provedor é conhecido como Harvest. No caso de portais baseados na tecnologia adotada pelo GBIF, o processo de Harvest, envolve etapas conforme descritas abaixo:

- Criação do Data Provider;

- Criação do RAP (Resource Access Point);

- Vinculação dos namespaces;

- Solicitação e obtenção dos resources do provedor;

- Solicitação e obtenção dos dados de indexação;

- Processo de replicação dos dados;

- Processo de consolidação dos dados replicados;

- Rotinas para contagem e adequação dos dados.

É importante ressaltar que, este apêndice não contempla as rotinas responsáveis pela criação ou atualização da árvore taxonômica. O motivo é que, o conteúdo adicional seria grande, e o mesmo não contribuiria satisfatoriamente para esta dissertação.

Nos tópicos a seguir, serão descritos os procedimentos básicos envolvidos em cada etapa do processo e seu resultado dentro do portal. Para realização desse processo, é necessário acesso direto ao banco de dados do portal, assim como, o código fonte dos módulos: portal-core e portal-index.

\subsection{Criação do Data Provider}

Esta etapa, assim como as duas seguintes, necessitam de inserção de informações diretamente no banco de dados do portal. O motivo é a não existência de uma ferramenta designada para estas etapas. Na tabela "data_provider" do banco de dados, deve ser inserido um novo registro contendo a única informação 
obrigatória (o nome do provedor), os demais campos devem ficar em branco, conforme pode-se ver na Figura 23.

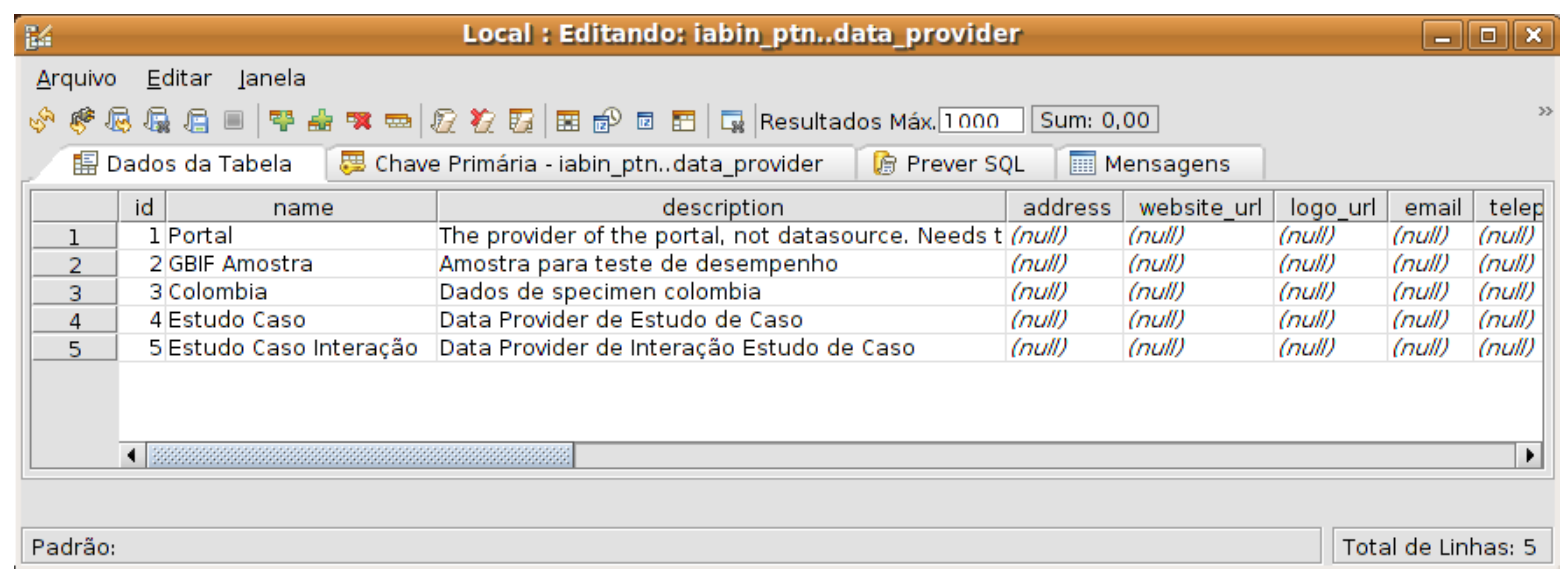

Figura 23 - Visualização de exemplo da tabela "data_provider"

\subsection{Criação do Resource Access Point}

Com o registro inserido, o mesmo recebe um identificador (id) automaticamente, deve-se tomar nota deste número, pois o mesmo é utilizado nesta etapa.

O portal utiliza um termo conhecido como RAP (Resource Access Point) para designar o concentrador do provedor. Este concentrador contém a URL de acesso remoto do mesmo. Assim sendo, na tabela "resource_access_point" do banco de dados do portal deve-se preencher três campos:

- data_provider_id : utiliza-se o mesmo identificador criado na etapa anterior;

- data_resource_id : utiliza-se como padrão o identificador "1";

- url : inseri-se a URL do provedor de dados.

Após a inserção, um novo identificador (id) será criado para esse novo RAP (conforme pode ser visto na Figura 24). Deve-se também tomar nota deste identificador, pois o mesmo será utilizado nas próximas etapas. 


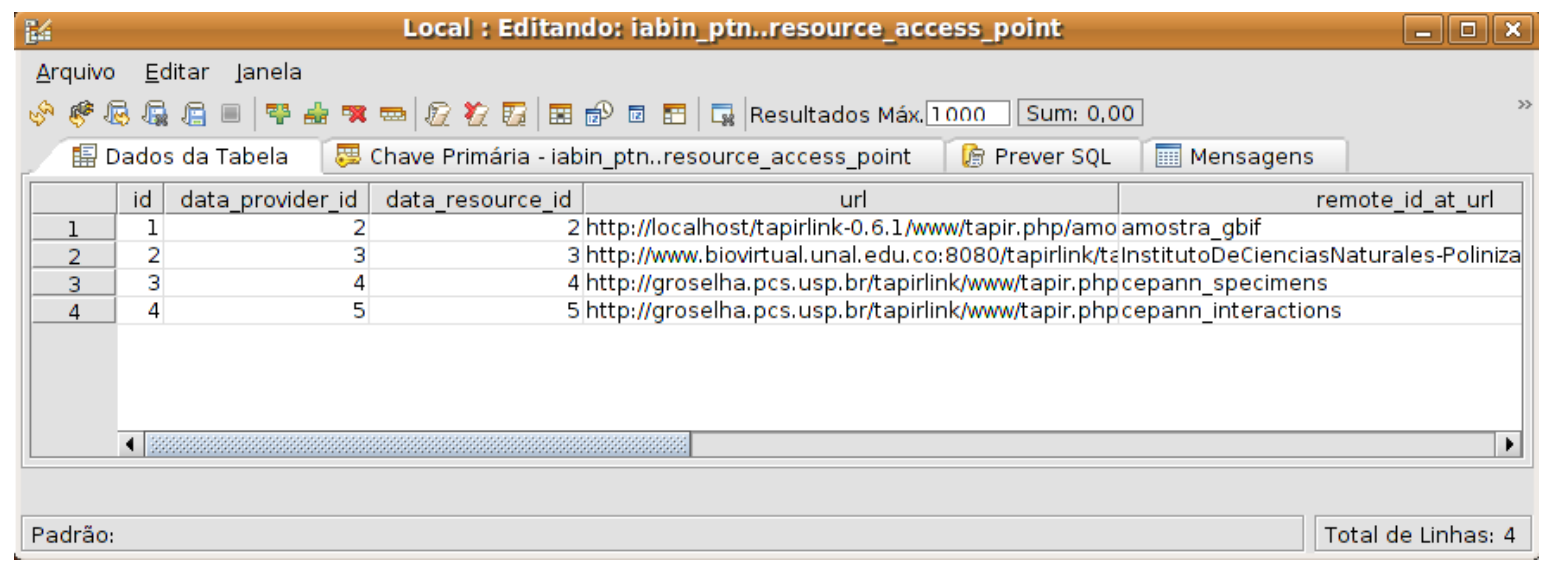

Figura 24 - Visualização de exemplo da tabela "resource_access_point"

\subsection{Vinculação dos namespaces}

Os namespaces são a lista de esquemas suportados pelo portal. Os mesmos são de fundamental importância no processo de Harvest, pois, é através desses vínculos que o portal define os padrões / esquemas de dados, os quais serão adotados na comunicação e armazenamento dentro do portal. O banco de dados do portal conta com a tabela "property_store_namespace", a qual possui a listagem de todos os modelos disponíveis, conforme pode-se ver através da Figura 25.

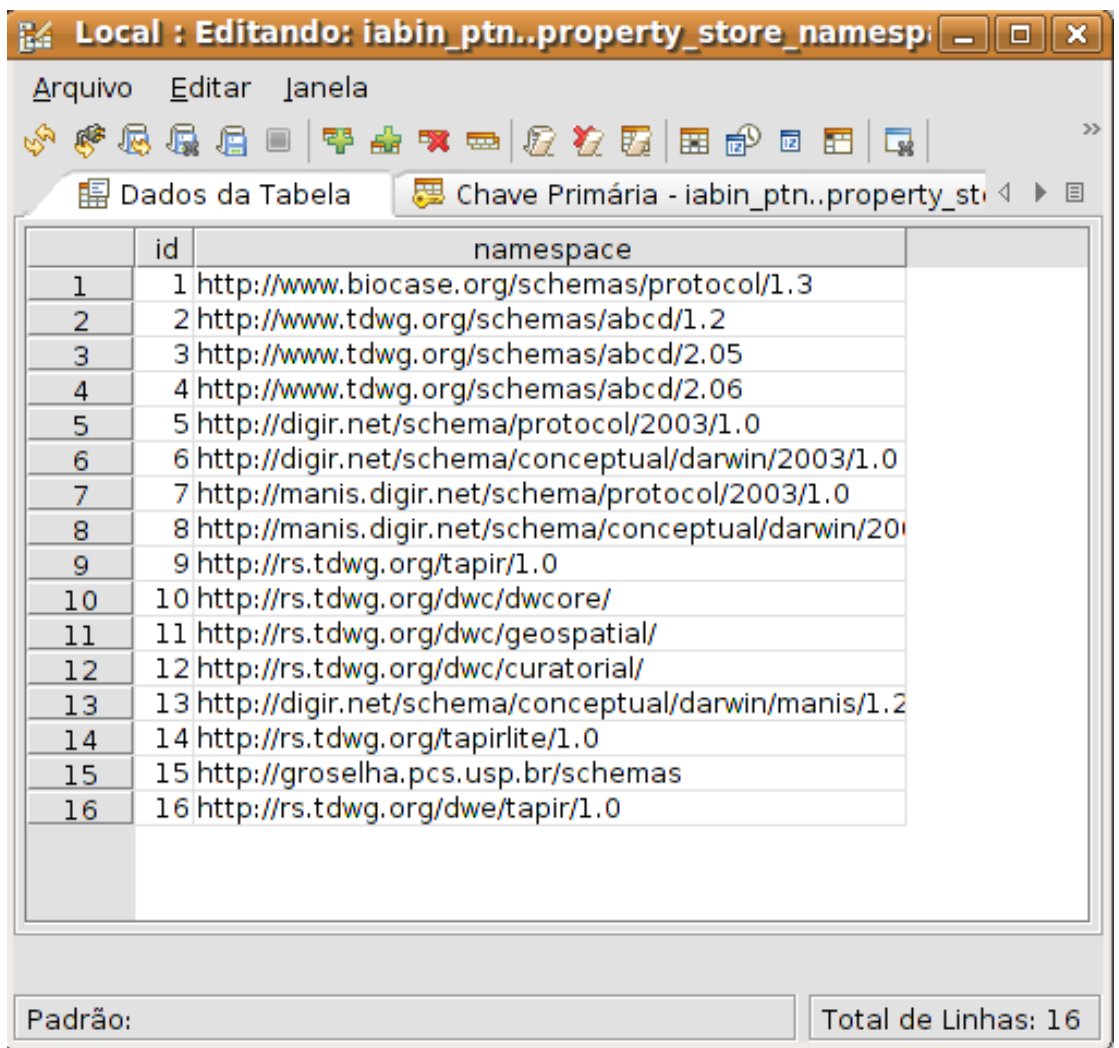

Figura 25 - Listagem de esquemas disponíveis para uso no portal 
Na tabela "namespace_mapping", é necessário indicar o identificador do RAP, e os modelos de dados com os quais o mesmo tem vínculo. Nessa inserção inicial, o campo "priority" deve permanecer com o valor "0". Cada registro indica um vínculo, conforme pode-se ver na Figura 26.

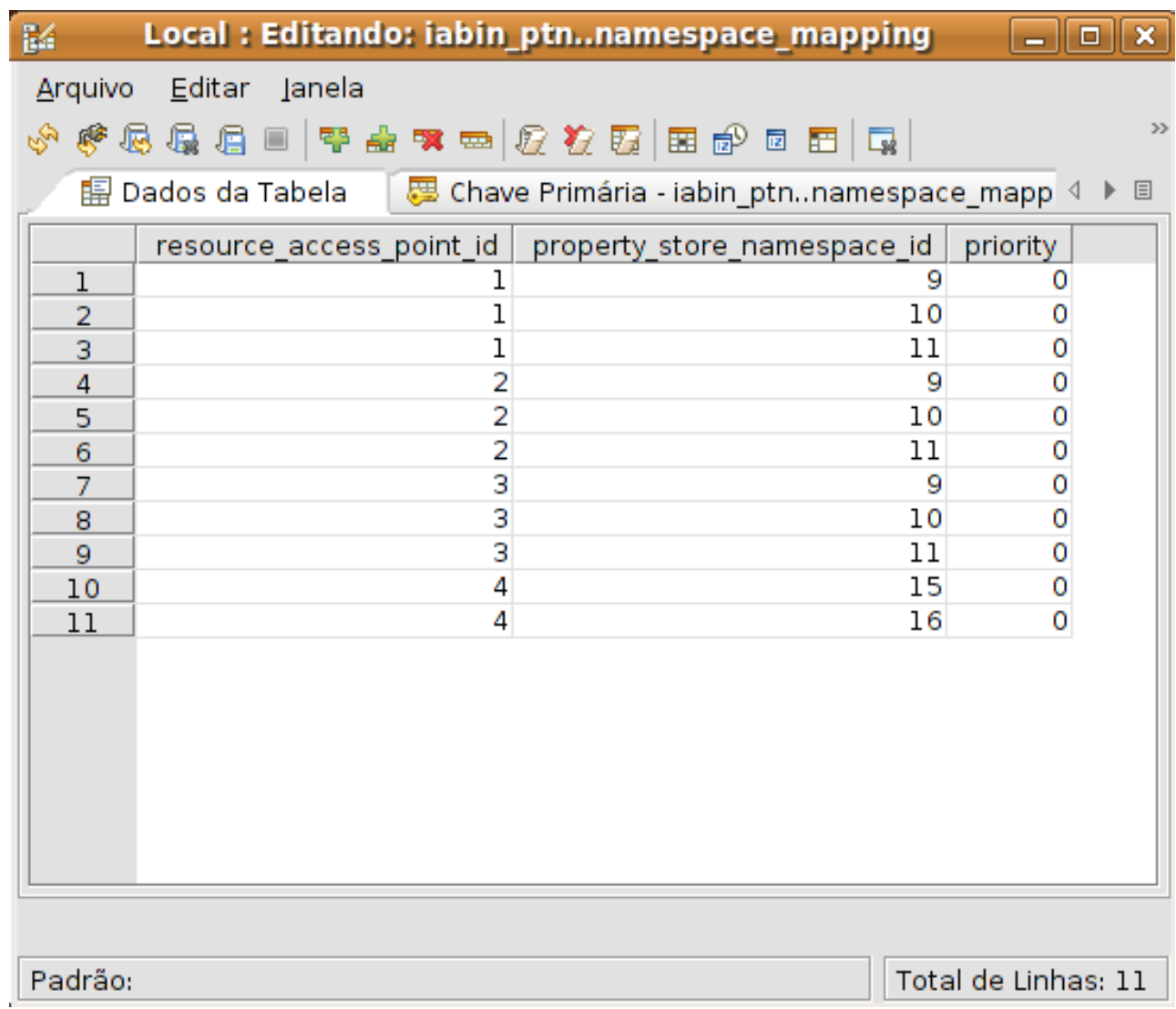

Figura 26 - Vínculos estabelecidos entre os RAP e os esquemas de dados

\subsection{Solicitação e obtenção dos resources do provedor}

A partir dessa etapa, é necessário o uso de uma IDE (Integrated Development Environment) Java, para iniciar as classes executoras. As classes executoras são rotinas escritas em Java, que realizam partes do processo. Todas as classes executoras utilizadas ficam no módulo portal-index.

Antes de executar essa etapa, é necessário saber o identificador do RAP do provedor (conforme citado anteriormente), o mesmo serve de parâmetro para as classes executoras a serem utilizadas a seguir. Na Figura 27 pode-se observar uma listagem de classes executoras na IDE Java (Eclipse). 


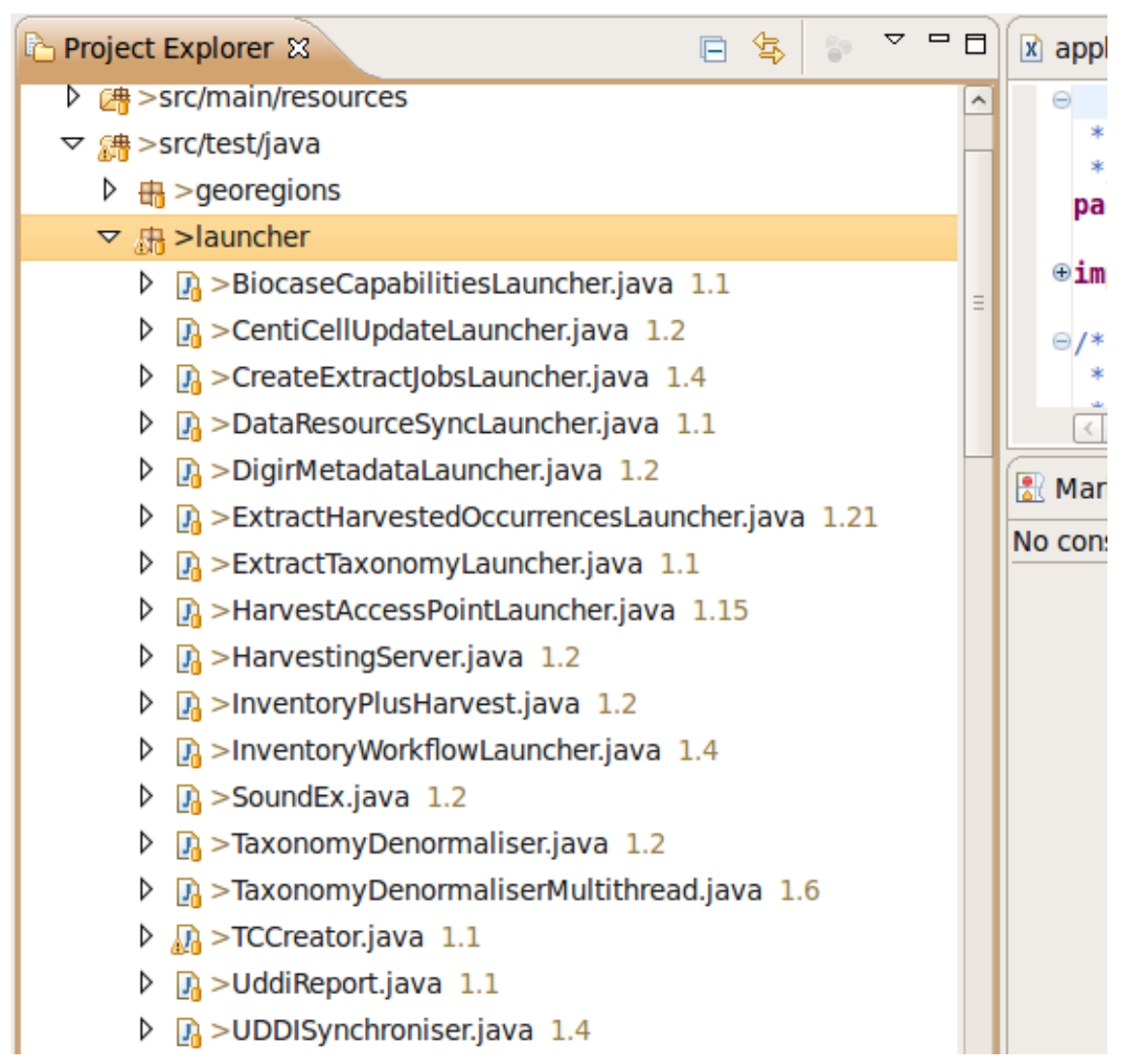

Figura 27 - Listagem de executores existentes no módulo portal-index

Apesar do nome pouco sugestivo, a primeira rotina a ser executada é a "DigirMetadataLauncher". A mesma é responsável por estabelecer uma comunicação inicial com o provedor, determinando a quantidade de resources, e os dados iniciais que o mesmo irá fornecer. Esse é um processo relativamente rápido perante os demais.

\subsection{Solicitação e obtenção dos dados de indexação}

Antes de efetuar a replicação dos dados, o portal solicita junto ao provedor a lista de indexação. Esta lista é composta por uma dupla de nomes científicos (no caso do DwC), uma inicial e uma final. O intervalo entre as mesmas determina quais registros serão enviados, facilitando o controle sobre as partes que já foram replicadas ou atualizadas.

O processo a ser executado é o "InventoryWorkflowLauncher", como parâmetro deve ser informado o identificador do RAP (como conhecido anteriormente) do provedor. 
Após a execução dessa etapa, a tabela "index_data" será preenchida, porém, não há necessidade de intervenção na base de dados, a menos que, seja necessário apagar e fazer o processo novamente.

\subsection{Processo de replicação de dados}

Nesse estágio do processo, será utilizado 0 executor "HarvestAccessPointLauncher", mantendo o uso do identificador do RAP do provedor como parâmetro. Essa etapa é responsável pela replicação dos dados entre o provedor e o portal.

O término do processo pode levar horas, ou em alguns casos, até mesmo dias. Uma vez finalizada, a tabela "raw_occurrence_record" será preenchida com os dados idênticos aos vindos do provedor.

\subsection{Processo de consolidação dos dados replicados}

Uma vez replicados, os dados passam por uma etapa que não requerem mais conexão com o provedor (por já estarem na base local do portal). Essa etapa, consiste em vincular os novos dados a realidade relacional da base de dados do portal. O resultado principal da consolidação fica armazenado na tabela "occurrence_record".

\subsection{Rotinas para contagem e readequação dos dados}

Neste ponto, os dados já podem ser visualizados no portal; no entanto, resta alguns ajustes a serem realizados. Estes ajustes são efetuados por uma rotina SQL, que gera dados de pré-visualização e de consolidação da árvore taxonômica.

A rotina SQL em questão fica localizada dentro do módulo portal-index, na pasta "db" e possui o nome de "process.sql". 